\title{
Xanthomonas campestris pv. vesicatoria Effector AvrBsT Induces Cell Death in Pepper, but Suppresses Defense Responses in Tomato
}

\author{
Nak Hyun Kim, Hyong Woo Choi, and Byung Kook Hwang \\ Laboratory of Molecular Plant Pathology, School of Life Sciences and Biotechnology, Korea University, Anam-dong, \\ Sungbuk-ku, Seoul 136-713, Republic of Korea
}

Submitted 11 July 2009. Accepted 29 March 2010.

\begin{abstract}
A type III effector protein, AvrBsT, is secreted into plant cells from Xanthomonas campestris pv. vesicatoria Bv5-4a, which causes bacterial spot disease on pepper (Capsicum annuum) and tomato (Solanum lycopersicum). To define the function and recognition of AvrBsT in the two host plants, avrBs $T$ was introduced into the virulent pepper strain $X$. campestris pv. vesicatoria Ds1. Expression of AvrBsT in Ds1 rendered the strain avirulent to pepper plants. Infection of pepper leaves with Ds1 (avrBsT) expressing AvrBsT but not with near-isogenic control strains triggered a hypersensitive response (HR) accompanied by strong $\mathrm{H}_{2} \mathrm{O}_{2}$ generation, callose deposition, and defense-marker gene expressions. Mutation of avrBsT, however, compromised HR induction by $X$. campestris pv. vesicatoria Bv5-4a, suggesting its avirulence function in pepper plants. In contrast, AvrBsT acted as a virulence factor in tomato plants. Growth of strains Ds1 (avrBsT) and Bv5-4a $\triangle a v r B s T$ was significantly enhanced and reduced, respectively, in tomato leaves. $X$. campestris pv. vesicatoria-expressed AvrBsT also significantly compromised callose deposition and defense-marker gene expression in tomato plants. Together, these results suggest that the $X$. campestris pv. vesicatoria type III effector AvrBsT is differentially recognized by pepper and tomato plants.
\end{abstract}

Plants perceive invading microorganisms using a sophisticated immune system that has been established through intimate but antagonistic coevolution. The plant immune system consists of basal defense or pathogen-associated molecular pattern (PAMP)-triggered immunity $(\mathrm{PTI})$ and resistance $(R)$ gene-mediated defense or effector-triggered immunity (ETI) (Jones and Dangl 2006). In PTI, PAMPs, which are conserved microbial components, act as ligands for the plant's patternrecognition receptor proteins (Göhre and Robatzek 2008). These proteins activate signaling pathways such as mitogenactivated protein kinase (MAPK) cascades to confer resistance (Asai et al. 2002). In ETI, pathogen effector proteins that are injected into the host cell via the type III secretion system

Corresponding author: Byung Kook Hwang; Telephone: +82-2-32903061; Fax: +82-2-921-1715; E-mail: bkhwang@korea.ac.kr

Nucleotide sequence data of $a v r B s T$ from this article can be found in the GenBank data libraries under accession number GQ266402.

* The $e$-Xtra logo stands for "electronic extra" and indicates that three supplementary figures are published online. Figures 5 and 8 also appear in color online.
(TTSS) are recognized by specific R proteins. Upon recognition of some effector proteins, host cells undergo rapid programmed cell death known as the hypersensitive response (HR) (Greenberg and Yao 2004). The effector proteins causing hypersensitive cell death in host plants are proposed to be avirulence proteins.

Some effector proteins have been shown to possess virulence functions when cognate $R$ genes are absent in host plants. Effector proteins target both the PTI and ETI systems (Boller and He 2009). The HopM1 effector protein from Pseudomonas syringae pv. tomato suppresses the deposition of callose in plants (DebRoy et al. 2004). The P. syringae pv. tomato HopAl1 effector, which functions as a phosphothreonine lyase, inhibits phosphorylation of the MAPK 3 (MPK3) and MAPK 6 (MPK6) (Zhang et al. 2007). Host signaling components are directly or indirectly degraded by effector proteins. AvrRpt 2 is a cysteine protease that cleaves the RPM1-interacting protein 4 (RIN4) protein of Arabidopsis, which may be involved in AvrRpm1 and AvrB recognition during ETI (Desveaux et al. 2007; Göhre and Robatzek 2008). Arabidopsis chitin elicitor receptor kinase 1 (CERK1) is ubiquitinated by AvrPtoB to promote bacterial virulence in plants (Gimenez-Ibanez et al. 2009). $P$. syringae pv. tomato type III effectors such as HopPtoE, AvrPphE $_{\text {Pto }}$, and AvrPtoB have been shown to suppress programmed cell death in plants (Jamir et al. 2004).

Xanthomonas campestris pv. vesicatoria causes bacterial spot disease on pepper (Capsicum annuum) and tomato (Solanum lycopersicum) plants. Some $X$. campestris pv. vesicatoria strains are virulent in both pepper and tomato plants (the pepper/tomato group), although most are virulent on only one of the two plants. $X$. campestris pv. vesicatoria strains that are virulent only to tomato (tomato group) cause HR-like cell death in pepper, and, conversely, X. campestris pv. vesicatoria strains that are virulent only to pepper (pepper group) are avirulent to tomato (Jones and Stall 1998). The principle of avirulence in the pepper or tomato groups was found to be controlled by the $a v r B s 4$ and $a v r B s T$ genes, respectively (Minsavage et al. 1990; Ciesieolka et al. 1999). X. campestris pv. vesicatoria Bv5-4a, which belongs to the tomato group, contains the effector protein AvrBsT (Jones and Stall 1998). Inoculation with strain Bv5-4a produces a strong HR-like cell death in pepper leaves (Lee and Hwang 2003, 2005). Cell death in pepper leaves is accompanied by strong induction of the salicylic acid (SA)-dependent gene CaBPRI (pepper basic pathogenesisrelated protein) and the accumulation of $\mathrm{H}_{2} \mathrm{O}_{2}$ (Lee and Hwang 2005; Choi et al. 2007). Transient avrBsT expression in pepper and Nicotiana benthamiana induces cell death (Orth el al. 2000; Escolar et al. 2001). 
AvrBsT contains a putative YopJ-like serine/threonine acetyl-transferase domain. Disruption of a conserved catalytic triad consisting of His, Glu, and Cys abolishes the cell death response in $N$. benthamiana (Orth el al. 2000). Thus, the enzymatic activity of AvrBsT seems to be closely related to the cell death phenotype. The AvrBsT orthologue YopJ was identified in Yersinia pestis, the causal agent of bubonic plague. YopJ has been shown to exhibit acetyl-transferase activity and inhibit MAPK and the nuclear factor $\kappa \mathrm{B}$ signaling pathway, thus suppressing animal innate immunity (Orth et al. 2000; Mukherjee et al. 2006). However, the X. campestris pv. vesicatoria effector AvrXv4, which also has significant homology to YopJ, has been demonstrated to function as a small ubiquitin-like modifier (SUMO) protease (Roden et al. 2004). Therefore, the precise enzymatic function of AvrBsT is yet to be determined.

In this study, we aimed to further characterize the function of the effector protein AvrBsT in pepper and tomato plants. We first cloned avrBsT from the $X$. campestris pv. vesicatoria Bv5-4a and introduced it into the $X$. campestris pv. vesicatoria Ds1, which is highly virulent to pepper plants (Hwang et al. 1995). Introduction of avrBsT rendered the virulent strain Ds1 avirulent to pepper. Strain Ds1 ( $a v r B s T$ ) expressing AvrBsT induced an HR-like cell death in pepper leaves, which was accompanied by $\mathrm{H}_{2} \mathrm{O}_{2}$ accumulation and increased expression of defense marker genes. In contrast, AvrBsT suppressed basal defense and enhanced bacterial growth in tomato leaves, indicating that AvrBsT acts as a virulence factor in tomato plants. Our further analyses of avrBsT mutation in $X$. campestris pv. vesicatoria Bv5-4a also supported its avirulence and virulence functions in pepper and tomato plants, respectively. Diverse growth of $X$. campestris pv. vesicatoria strains Ds1 (avrBsT) and Bv54a $\Delta a v r B s T$ was suggestive of distinct functions of AvrBsT in both host plants. Recognition of AvrBsT by host plants required the $\mathrm{N}$ - and C-terminal domains of the protein. Together, these results identified AvrBsT as a key effector protein that induces or suppresses cell death and defense responses in pepper or tomato plants, respectively.

\section{RESULTS}

\section{$X$. campestris pv. vesicatoria Bv5-4a harbors a functional avrBsT gene.}

The $X$. campestris pv. vesicatoria Ds1 that is highly virulent to pepper plants was isolated in 1991 from diseased pepper leaves in Korea (Hwang et al. 1995). Strain Bv5-4a, which induces HR in pepper plants, was generously provided by $\mathrm{R}$. E. Stall. Interestingly, Bv5-4a triggered HR in all the pepper cultivars tested (Lee et al. 1994; Hwang et al. 1995). In our previous studies, we successfully isolated defense-related genes from pepper leaves infected by the avirulent strain Bv5-4a (Jung and Hwang 2000; Do et al. 2003; Lee and Hwang 2003, 2005; Choi et al. 2007, 2008, 2009; An et al. 2008a,b; Lee et al. 2008). Thus, we used DNA from Bv5-4a cells as a template to amplify the $a v r B s T$ open reading frame
(ORF) (Supplementary Fig. 1A). Sequence analysis of the amplicon revealed that avrBsT of Bv5-4a contained a minor variation compared with that of strain 75-3. However, this sequence difference did not interfere with the ability of AvrBsT to elicit cell death (Supplementary Fig. 3). The near-isogenic Ds1 strains expressing empty vector (EV) and $a v r B s T$, referred to as Ds1 (EV) and Ds1 (avrBsT), respectively, were further generated to identify the function of AvrBsT in planta. Immunoblot analyses also were performed to determine whether AvrBsT proteins expressed in X. campestris pv. vesicatoria are secreted by the TTSS (Supplementary Fig. 2). AvrBsT:cMyc fusion proteins were detected in whole-cell lysates from $X$. campestris pv. vesicatoria strains Ds1 (avrBsT:cMyc) and Ds1 $\Delta h r c V(a v r B s T: c M y c)$. However, the negative control strain Ds1 $\Delta h r c V(a v r B s T: c M y c)$ failed to secrete the protein into the culture medium. The $h r c V$ gene encodes an inner membrane protein of the TTSS and its mutation abolished the secretion of effector proteins from $X$. campestris pv. vesicatoria (Rossier et al. 1999). These data indicated that AvrBsT of $X$. campestris pv. vesicatoria is secreted in a TTSS-dependent manner.

\section{AvrBsT attenuates the virulence of $X$. campestris pv. vesicatoria Ds1 in pepper leaves.}

To examine in planta function of AvrBsT, pepper leaves were infiltrated with a low titer $\left(5 \times 10^{4} \mathrm{CFU} \mathrm{ml}{ }^{-1}\right)$ of the $X$. campestris pv. vesicatoria strains Ds1, Ds1 (EV), Ds1 (avrBsT), and Bv5-4a (Fig. 1A). Seventeen days after inoculation, Ds1 and Ds1 (EV) induced severe chlorosis and Ds1 (avrBsT) induced mild chlorosis, whereas Bv5-4a did not produce any visible symptoms on pepper leaves. When observed under UV light, chlorosis was apparent only in pepper leaves inoculated with Ds1 and Ds1 (EV) (Fig. 1A). Bacterial growth was measured $0,3,6$, and 9 days after inoculation. The growth of Ds 1 (avrBsT) was significantly retarded 10-fold compared with that of Ds1 and Ds1 (EV) but was 10-fold higher than that of Bv5-4a (Fig. 1B). Ds1 and Ds1 (EV) continued to grow 6 days after inoculation but the growth of Ds1 ( $a v r B s T)$ was arrested, similar to that of the avirulent strain Bv5-4a.

Pepper leaves infiltrated with a high titer $\left(10^{8} \mathrm{CFU} \mathrm{ml}^{-1}\right)$ of Ds1 (avrBsT) and Bv5-4a exhibited a typical HR, whereas Ds1- and Ds1 (EV)-infiltrated leaves did not show any visible symptoms 2 days after inoculation. UV light illumination revealed that leaves infiltrated with Ds1 (avrBsT) and Bv5-4a accumulated defense-related fluorescent phenolics at the site of infiltration (Fig. 1C) (Choi et al. 2009). Plant cells undergoing programmed cell death release electrolytes into extracellular spaces. Thus, ion leakage measurement has been used as an indicator of plant cell death (Baker et al. 1991). When pepper leaves were challenged with a high titer $\left(5 \times 10^{7} \mathrm{CFU}\right.$ $\mathrm{ml}^{-1}$ ) of $X$. campestris pv. vesicatoria, Bv5-4a triggered a drastic increase in the level of electrolyte leakage 12,24 , and $35 \mathrm{~h}$ after inoculation (Fig. 1D). Induction of electrolyte leakage by Ds1 (avrBsT) infection was not as strong as that by Bv5-4a infection; however, its induction level was significantly higher

Fig. 1. AvrBsT attenuates the virulence of the Xanthomonas campestris pv. vesicatoria Ds1 in pepper leaves. A, Disease symptoms of pepper leaves caused by $X$. campestris pv. vesicatoria strains. Pepper leaves were inoculated with the indicated strains $\left(5 \times 10^{4} \mathrm{CFU} \mathrm{ml}^{-1}\right)$ and photographed 17 days later. $\mathbf{B}$, Measurement of bacterial growth. Pepper leaves were inoculated with the indicated strains $\left(5 \times 10^{4} \mathrm{CFU} \mathrm{ml}^{-1}\right)$. Bacterial growth in leaves was measured at different time points after inoculation. Different letters indicate statistically significant differences (least significant difference [LSD]; $P<0.05$ ). C, Response of pepper leaves to high bacterial titers. Pepper leaves were inoculated with the indicated strains $\left(10^{8} \mathrm{CFU} \mathrm{m}^{-1}\right)$ and photographed $40 \mathrm{~h} \mathrm{later.} \mathbf{D}$, Measurement of electrolyte leakage. Pepper leaves were inoculated with indicated strains $\left(5 \times 10^{7} \mathrm{CFU} \mathrm{ml}^{-1}\right)$. Electrolyte leakage caused by cell death was monitored at the indicated time points after inoculation. Different letters indicate statistically significant differences (LSD; $P<0.05)$. E, Histochemical analyses. Pepper leaves were inoculated with the indicated strains $\left(5 \times 10^{7} \mathrm{CFU} \mathrm{ml}^{-1}\right)$. Leaves were stained with aniline blue, 3,3'-diaminobenzidine (DAB), and trypan blue 12,24 , and $36 \mathrm{~h}$ after inoculation, respectively. Bars $=250 \mu \mathrm{m}$ (aniline blue), $500 \mu \mathrm{m}$ (DAB), and $500 \mu \mathrm{m}$ (trypan blue). Experiments were repeated three times with similar results. Data in B and D are means \pm standard deviations from three independent experiments. 


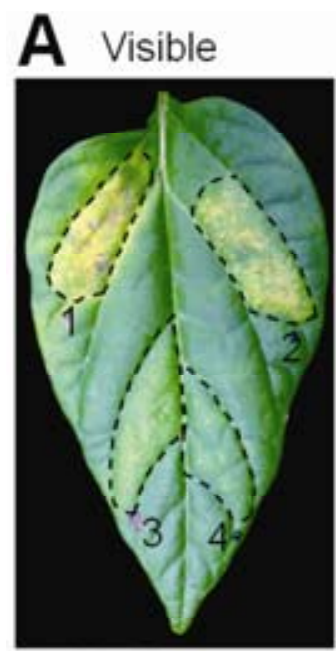

1. $X c v D s 1$

3. $X_{c v}$ Ds1(avrBsT)

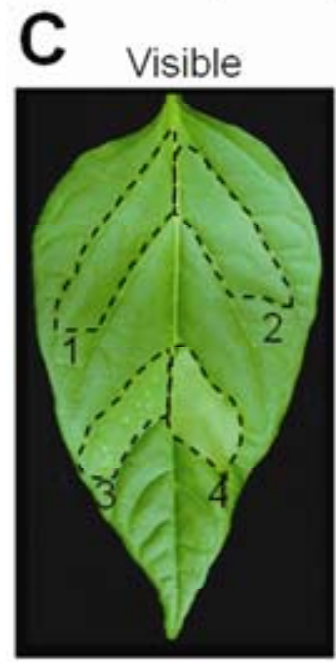

1. Xov Ds1

3. $X c v$ Ds1(avrBsT)

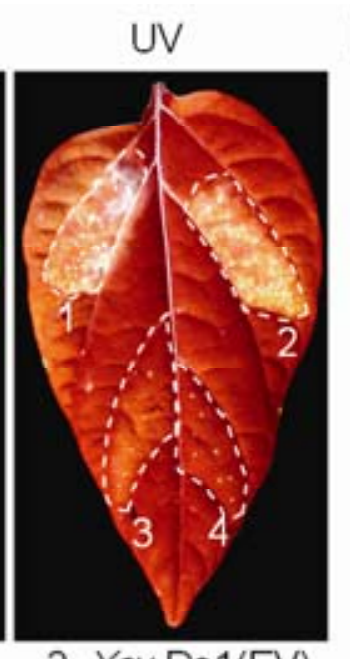

2. Xcv Ds1(EV)

4. $X_{c v}$ Bv5-4a

$\mathbf{B} \square \mathrm{Ds} 1 \square \mathrm{Ds} 1(\mathrm{EV}) \square \mathrm{Ds} 1(\mathrm{avr} B s T) \square \mathrm{Bv5}-4 \mathrm{a}$

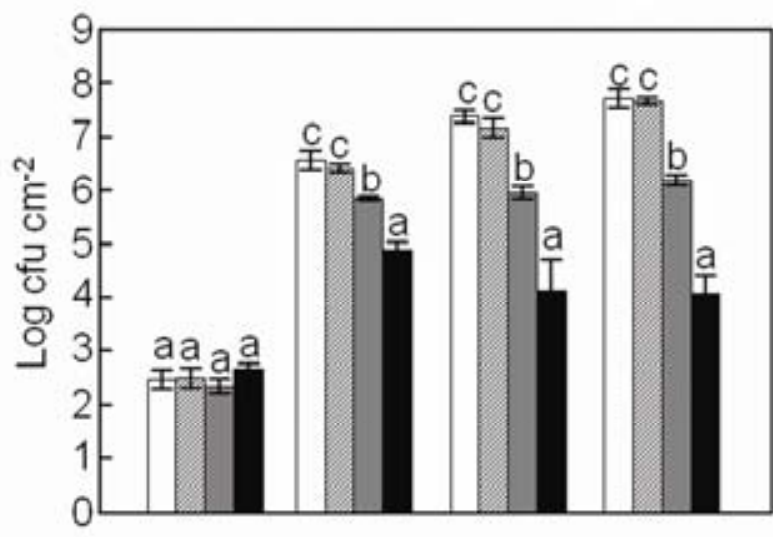

0

3

6

9

Days after inoculation

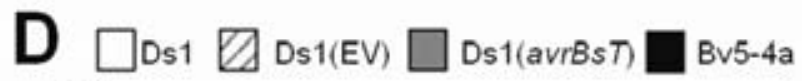

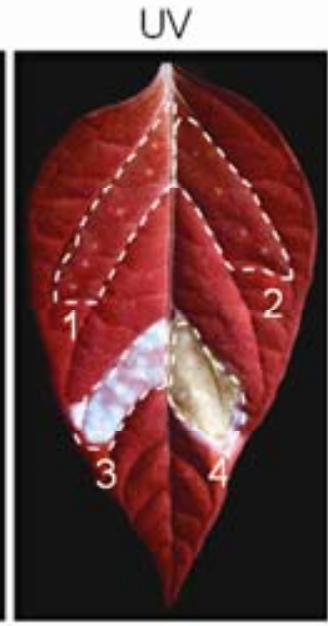

2. Xov Ds1(EV)

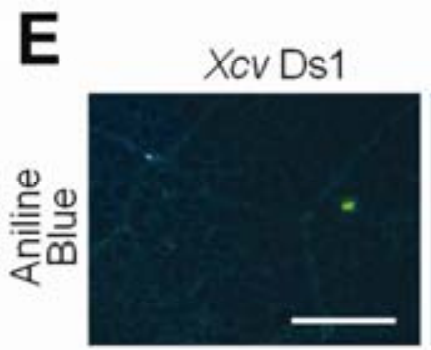

$X_{C V}$ Ds1(EV)
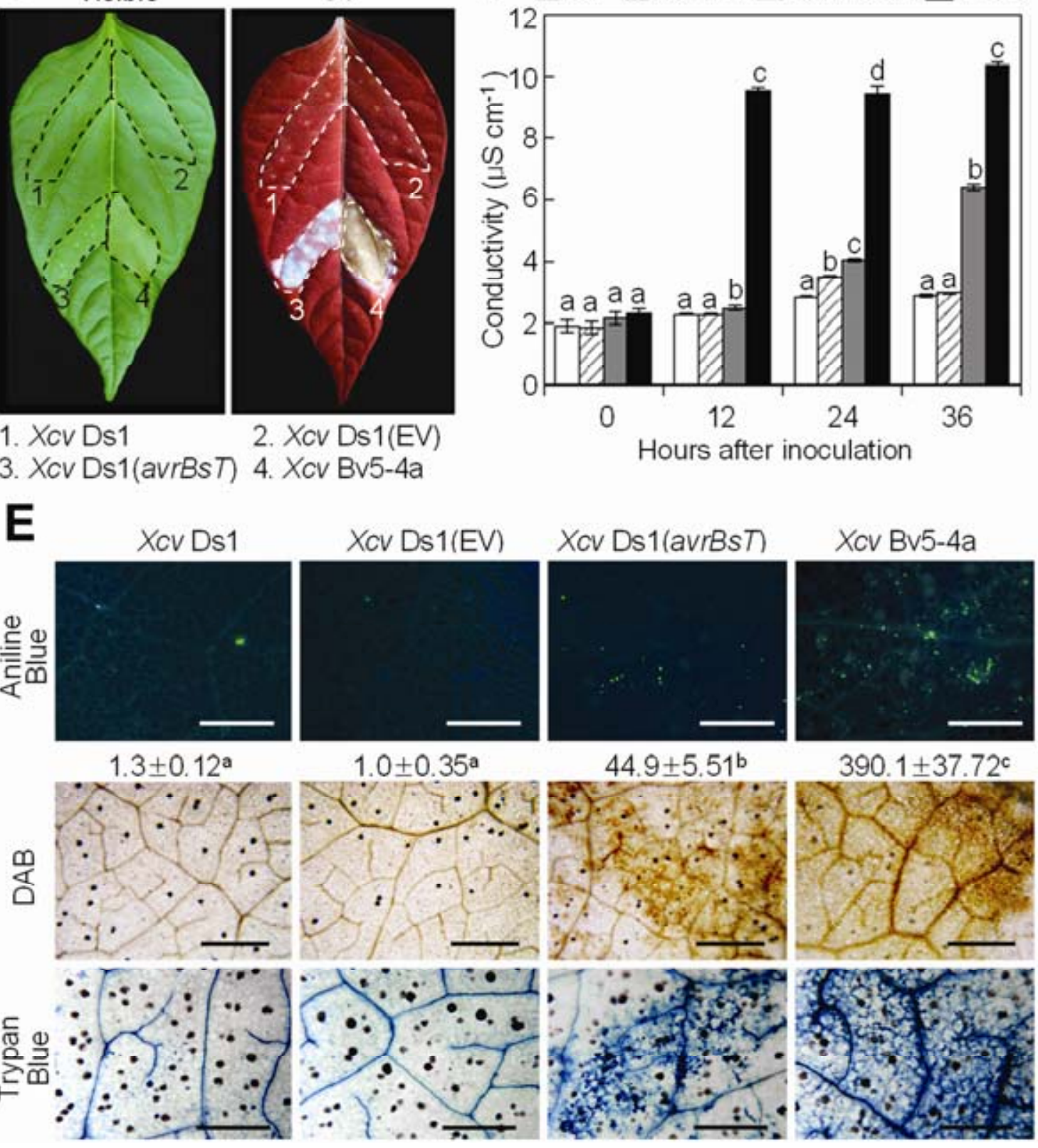

$1.0 \pm 0.35^{a}$

$44.9 \pm 5.51^{\text {b }}$

$390.1 \pm 37.72^{\mathrm{c}}$

Hours after inoculation
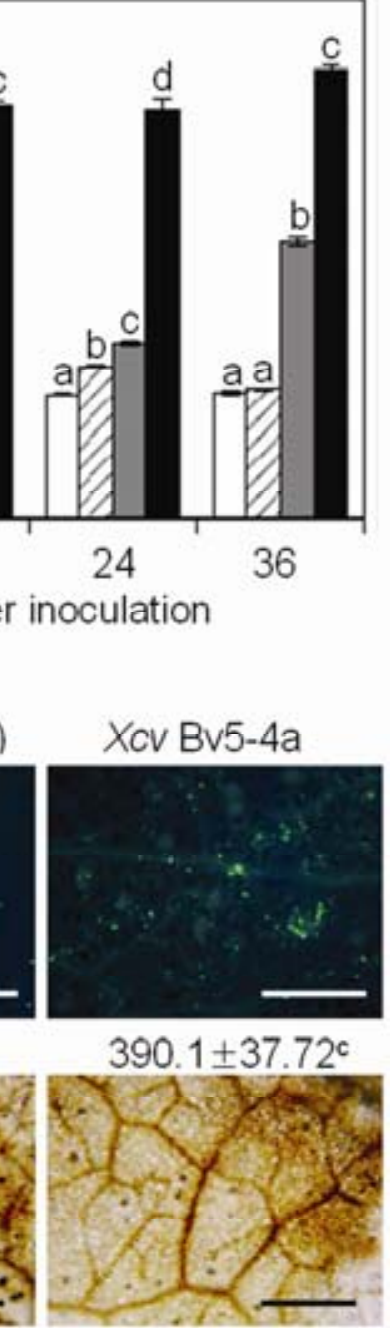

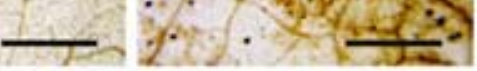

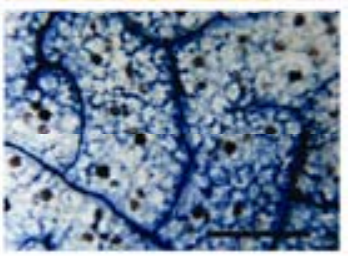


than Ds1- or Ds1 (EV)-induced ones. Electrolyte leakage in Ds1- and Ds1 (EV)-infiltrated leaves slightly increased at $24 \mathrm{~h}$ but returned to a basal level $36 \mathrm{~h}$ after inoculation.

To define the defense response of pepper plants at the cellular level, various histochemical analyses were performed on pepper leaves infiltrated with high titers of $X$. campestris pv. vesicatoria strains $\left(5 \times 10^{7} \mathrm{CFU} \mathrm{ml}^{-1}\right)$ (Fig. 1E). Infection with Ds1 (avrBsT) and Bv5-4a but not with Ds1 and Ds1 (EV) triggered callose deposition in pepper leaves. Leaves inoculated with Ds1 (avrBsT) and Bv5-4a strongly accumulated $\mathrm{H}_{2} \mathrm{O}_{2}$ compared with Ds1 and Ds1 (EV) when detected by 3,3'-diaminobenzidine (DAB, a histochemical reagent for $\mathrm{H}_{2} \mathrm{O}_{2}$ ) staining. Trypan blue staining of pepper leaves also revealed the induction of HR-like cell death by Ds1 ( $a v r B s T)$ and Bv5-4a but not by Ds1 and Ds1 (EV). These findings suggest that the trans- formation of avrBsT into Ds1 rendered this strain avirulent in pepper plants.

\section{AvrBsT functions as a key avirulence factor}

of the $X$. campestris pv. vesicatoria Bv5-4a in pepper leaves.

To determine whether AvrBsT functions as an avirulence factor in plants, the deletion mutants were generated from strain Bv5-4a by using site-directed mutagenesis (Lee et al. 2009). Bv5-4a $\triangle a v r B s T$ but not Bv5-4a and Bv5-4a $\Delta a v r B s T$ (avrBsT) induced severe brownish bacterial spots on pepper leaves 14 days after infiltration with a low titer $\left(5 \times 10^{4} \mathrm{CFU} \mathrm{ml}{ }^{-1}\right)$ of $X$. campestris pv. vesicatoria (Fig. 2A). Bacterial growth also was measured $0,3,6$, and 9 days after inoculation (Fig. 2B). The growth of Bv5-4a $\triangle a v r B s T$ significantly increased 10-fold higher than that of Bv5-4a and Bv5-4a $\triangle a v r B s T$ (avrBsT) dur-

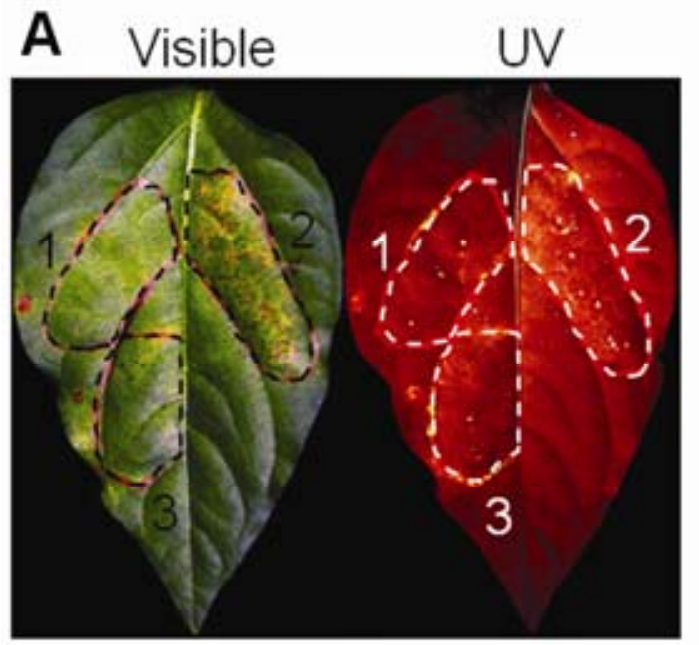

1. Xcv Bv5-4a 2. Xcv $\triangle a v r B s T$

3. Xcv $\triangle a v r B s T$ (avrBsT)

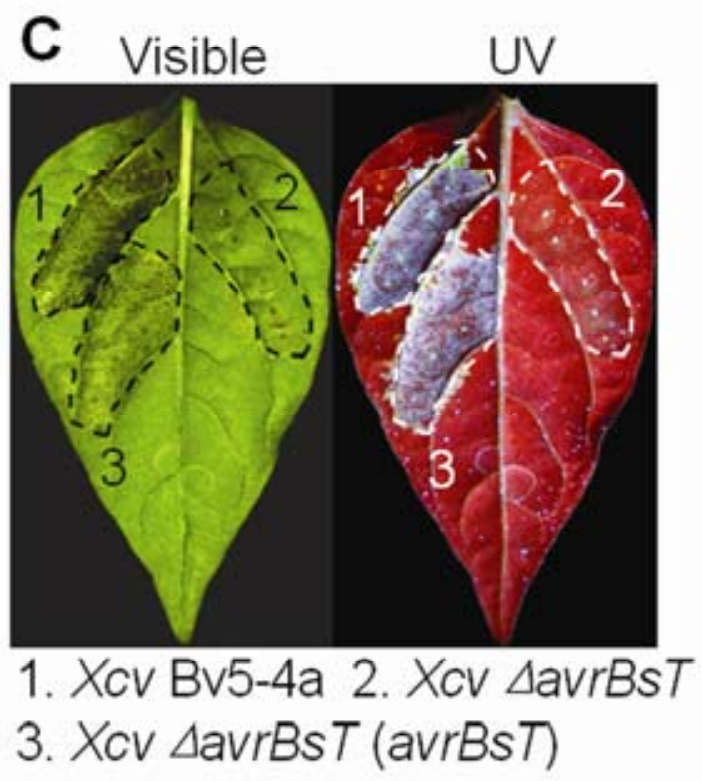

B

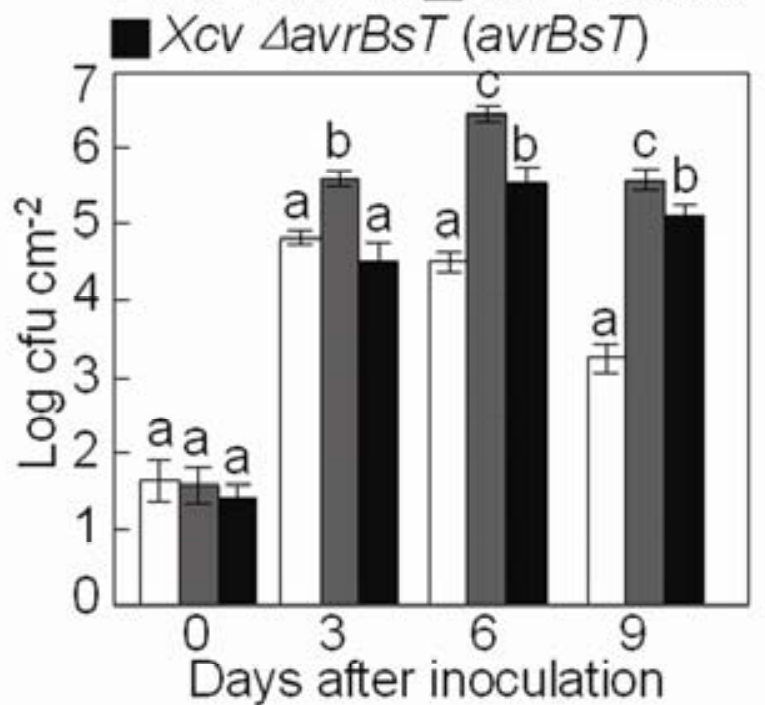

D $\square X c v B v 5-4 a \square X c v \Delta a v r B s T$

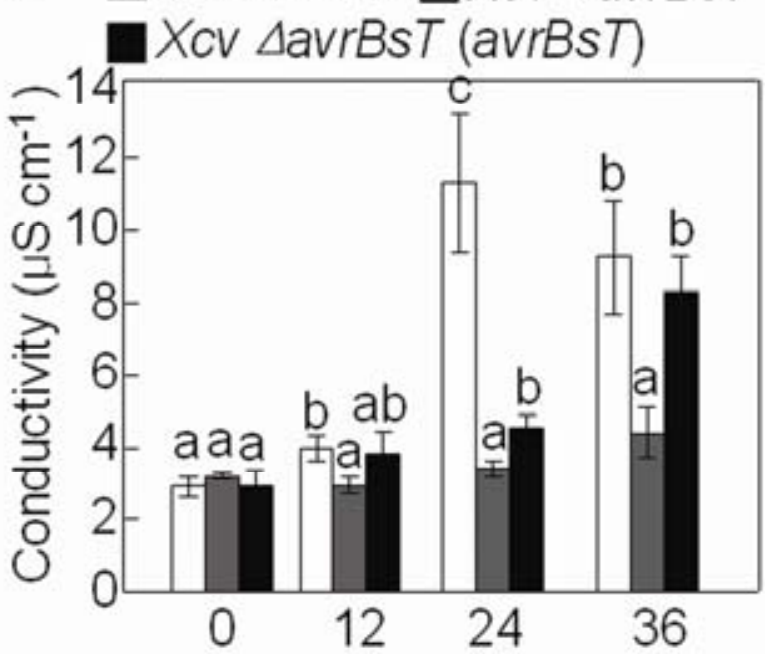

Hours after inoculation

Fig. 2. AvrBsT functions as a key avirulence factor of the Xanthomonas campestris pv. vesicatoria Bv5-4a in pepper leaves. A, Disease symptoms of pepper leaves caused by $X$. campestris pv. vesicatoria strains. Pepper leaves were inoculated with the indicated strains $\left(5 \times 10^{4} \mathrm{CFU} \mathrm{ml}^{-1}\right)$ and photographed 14 days later. B, Measurement of bacterial growth. Pepper leaves were inoculated with the indicated strains $\left(5 \times 10^{4} \mathrm{CFU} \mathrm{ml}{ }^{-1}\right)$. Bacterial growth in leaves was measured on indicated days after inoculation. Different letters indicate statistically significant differences (least significant difference [LSD]; $P<0.05$ ). C,

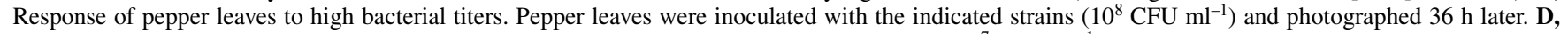
Measurement of electrolyte leakage. Pepper leaves were inoculated with indicated strains $\left(5 \times 10^{7} \mathrm{CFU} \mathrm{m}^{-1}\right)$. Electrolyte leakage caused by cell death was monitored at the indicated time points after inoculation. Different letters indicate statistically significant differences $(\mathrm{LSD} ; P<0.05)$. 
ing infection. The increased growth of avrBsT-mutated Bv5-4a supported the susceptible lesions caused by this $X$. campestris pv. vesicatoria mutant.

Pepper leaves infiltrated with a high titer $\left(10^{8} \mathrm{CFU} \mathrm{ml}^{-1}\right)$ of Bv5-4a and Bv5-4a $\Delta a v r B s T$ (avrBsT) exhibited a typical HR, whereas Bv5-4a $\triangle a v r B s T$ did not show any visible symptoms 2 days after inoculation. UV light illumination also showed the compromised accumulation of defense-related fluorescent phenolics at the site of infiltration with Bv5-4a $\Delta a v r B s T$ (Fig. 2C). Measurements of electrolyte leakage supported significantly attenuated cell death in pepper leaf tissues inoculated with Bv5-4a $\Delta a v r B s T$ compared with Bv5-4a and Bv5-4a $\triangle a v r B s T$ (avrBsT) (Fig. 2D). Together, these findings strongly suggest that the deletion of $a v r B s T$ from Bv5-4a rendered this strain virulent in pepper plants.

\section{AvrBsT induces defense-related gene expression} in pepper leaves.

To determine whether the reduced virulence of strain Ds1 $(a v r B s T)$ is due to the altered defense response in pepper plants, we further analyzed the transcript levels of some defense-related genes (CaBPR1, CaPO2, CaSAR82A, and $C a D E F 1)$ in pepper leaves infected with $X$. campestris pv. vesicatoria (Fig. 3) (Lee and Hwang 2005; Choi et al. 2007). Strain Bv5-4a and Ds1 (avrBsT) infection drastically induced $C a B P R 1$ and $\mathrm{CaPO} 2$ expression in pepper leaves compared with the virulent Ds1 and Ds1 (EV) infection. Notably, increase in $C a B P R 1$ transcript was strikingly strong in pepper leaves at an early time, $12 \mathrm{~h}$ after inoculation with Ds1 (avrBsT) and Bv5-4a. The transcript level of $\mathrm{CaPO} 2$ in pepper leaves infected with Bv5-4a and Ds1 (avrBsT) was approximately 10,000-fold higher than in those infected by Ds1 and Ds1 (EV) $12 \mathrm{~h}$ after inoculation (Fig. 3). The pepper defense-related CaSAR82A gene was also rapidly induced in pepper leaves 12 $\mathrm{h}$ after inoculation with Bv5-4a and Ds1 (avrBsT) (Fig. 3). $\mathrm{C} a D E F 1$ was sevenfold higher in pepper leaves inoculated with Ds1 (avrBsT) compared with Ds1 and Ds1 (EV). These data suggest that AvrBsT elicits defense-related gene expression in pepper plants, thus rendering Ds1 ( $a v r B s T)$ avirulent in pepper plants.
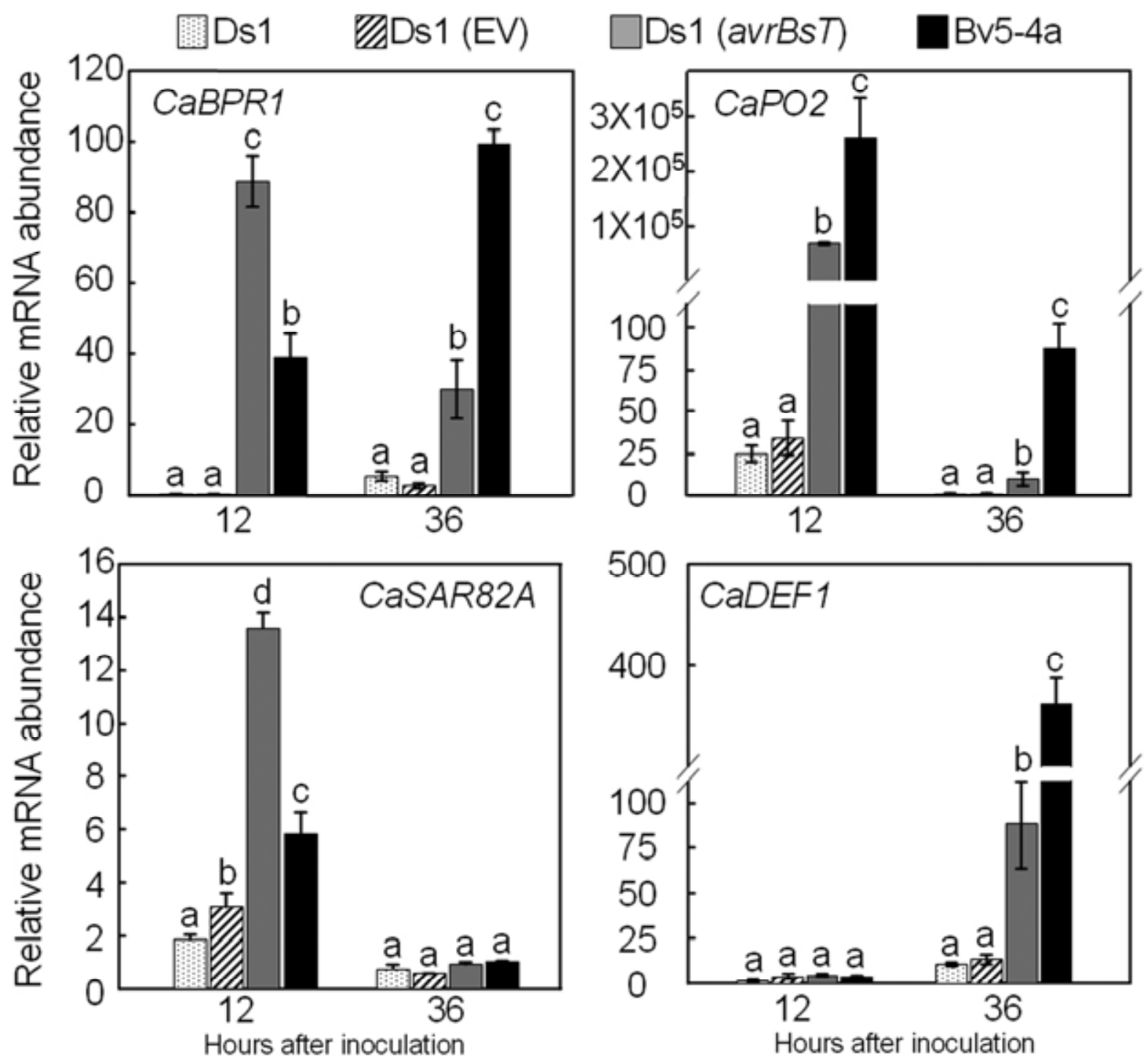

Fig. 3. AvrBsT induces pathogenesis-related $(P R)$ gene expression in pepper leaves. Total RNA was isolated from pepper leaves inoculated with Xanthomonas campestris pv. vesicatoria strains Ds1, Ds1 (empty vector [EV]), Ds1 (avrBsT), and Bv5-4a $\left(5 \times 10^{7} \mathrm{CFU} \mathrm{ml}^{-1}\right)$. Quantitative real-time polymerase chain reaction was performed for pepper $P R$ genes $C a B P R 1$ (basic PR1), CaPO2 (peroxidase 2), CaSAR82A (SAR8.2), and CaDEF1 (defensin). Abundance of mRNA 12 and $36 \mathrm{~h}$ after inoculation are shown. mRNA levels of $18 \mathrm{~S}$ rRNA were used for normalization of mRNA abundance in each sample. Different letters indicate statistically significant differences (least significant difference; $P<0.05$ ). Experiments were repeated three times with similar results. Data are means \pm standard deviations from three independent experiments. 
A Visible UV B

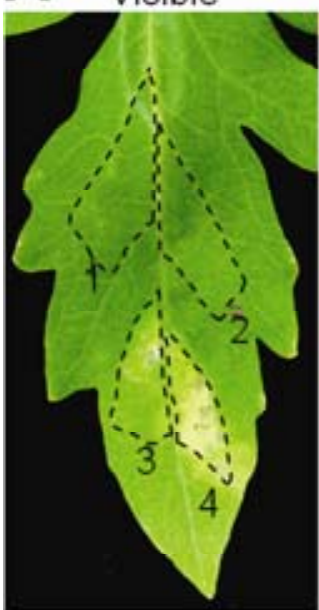

1. Xcv Ds1

3. Xcv Ds1(avrBsT)

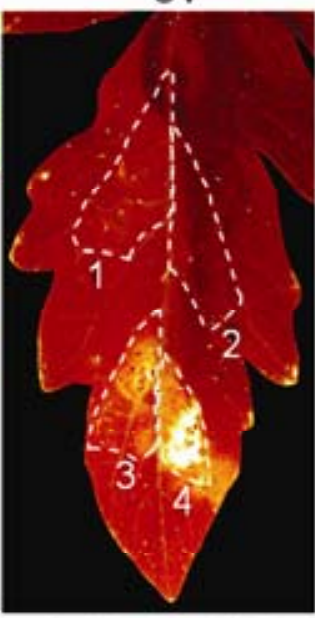

2. $X c v D s 1(E V)$

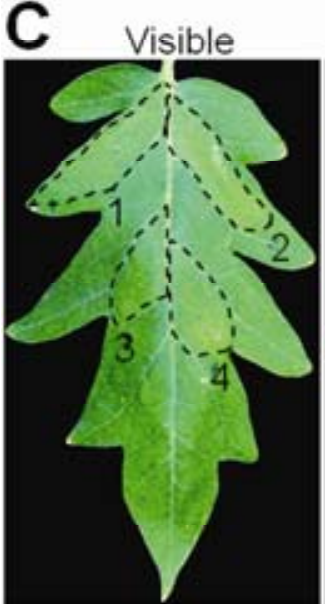

1. $X c v$ Ds 1

3. $X c v$ Ds1(avrBsT)

4. $X c v$ Bv5-4a

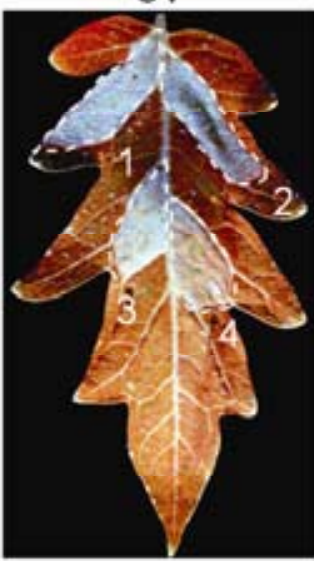

2. Xcv Ds1(EV)

4. Xov Bv5-4a

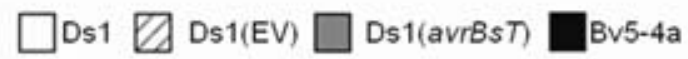

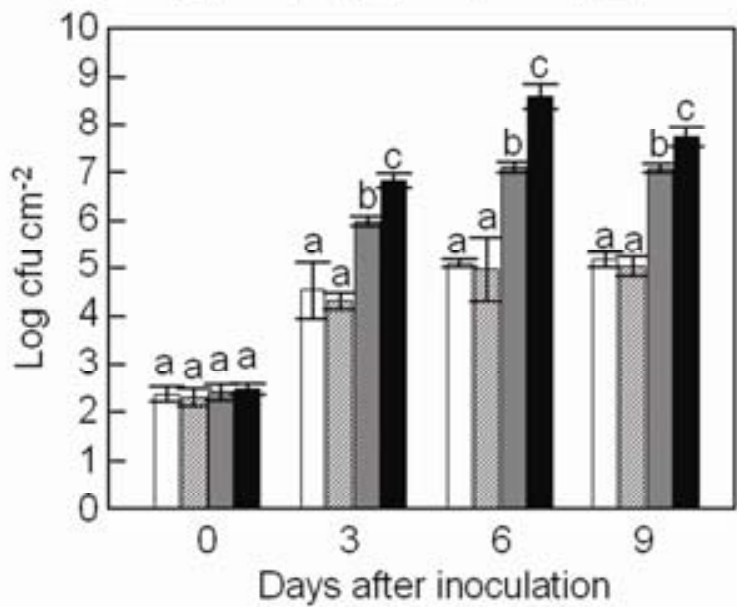

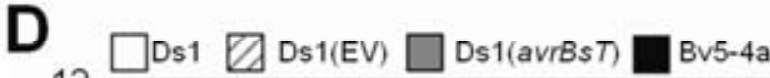

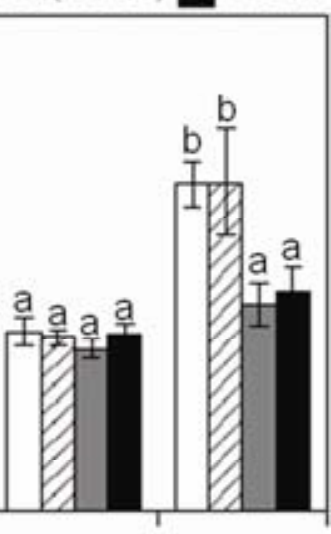

48

72

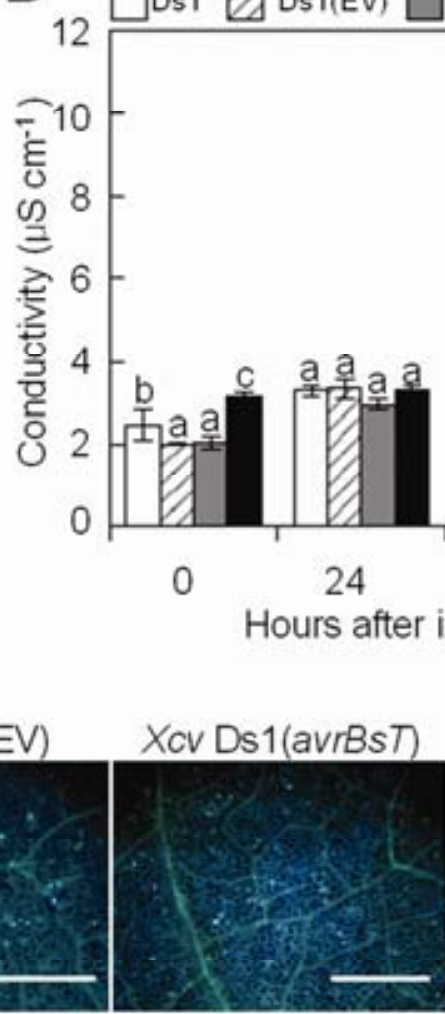

$36 \pm 3^{a}$

E

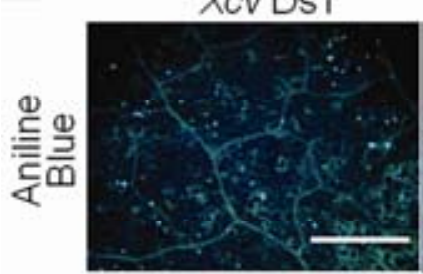

X $\mathrm{Cv}$ Ds $1(\mathrm{EV})$

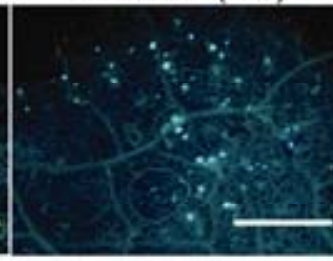

$70 \pm 5^{b}$

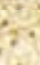

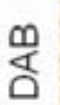

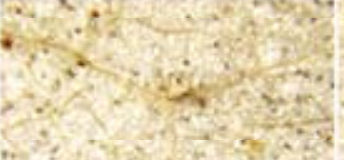

$x^{2}$

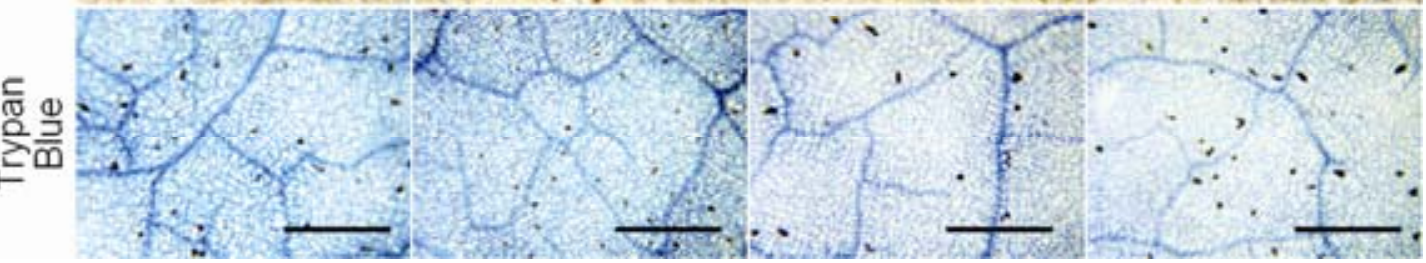


Fig. 4. AvrBsT promotes virulence of the Xanthomonas campestris pv. vesicatoria Ds 1 in tomato leaves. A, Disease symptoms of tomato leaves caused

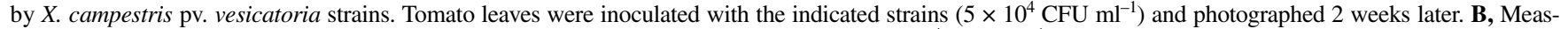
urement of bacterial growth. Tomato leaves were inoculated with the indicated strains $\left(5 \times 10^{4} \mathrm{CFU} \mathrm{ml}^{-1}\right)$. Bacterial growth in leaves was measured at different time points after inoculation. Different letters indicate statistically significant differences (least significant difference [LSD]; $P<0.05$ ). C, Response of tomato leaves to a high bacterial titer. Tomato plants were inoculated with the indicated strains $\left(5 \times 10^{7} \mathrm{CFU} \mathrm{ml}^{-1}\right)$ and were photographed $48 \mathrm{~h} \mathrm{later.} \mathbf{D}$, Electrolyte leakage measurement. Tomato plants were inoculated with indicated strains $\left(5 \times 10^{7} \mathrm{CFU} \mathrm{ml}^{-1}\right)$. Electrolyte leakage caused by cell death was monitored at indicated time points after inoculation. Different letters indicate statistically significant differences (LSD; $P<0.05)$. E, Histochemical analyses. Tomato leaves were inoculated with the indicated strains $\left(5 \times 10^{7} \mathrm{CFU} \mathrm{ml}^{-1}\right)$. Leaves were stained with aniline blue, $3,3^{\prime}$-diaminobenzidine, and trypan blue 12,24 , and $36 \mathrm{~h}$ after inoculation, respectively. Bars $=500 \mu \mathrm{m}$. Experiments were repeated three times with similar results. Data in B and D are means \pm standard deviations from three independent experiments.
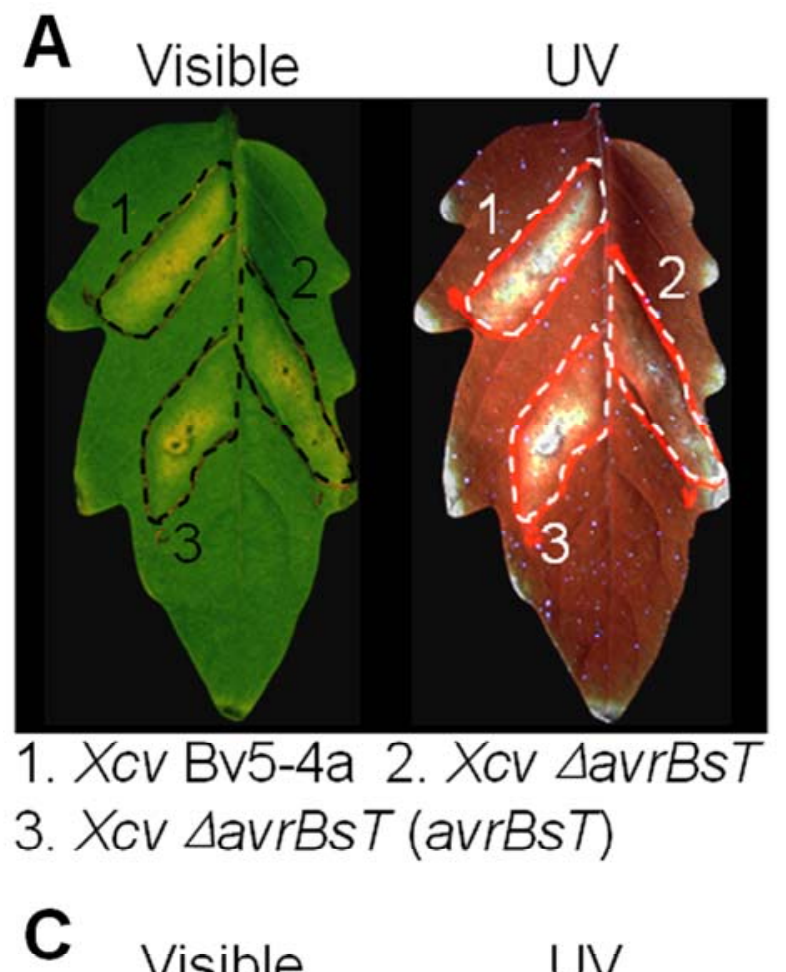

\section{Visible}

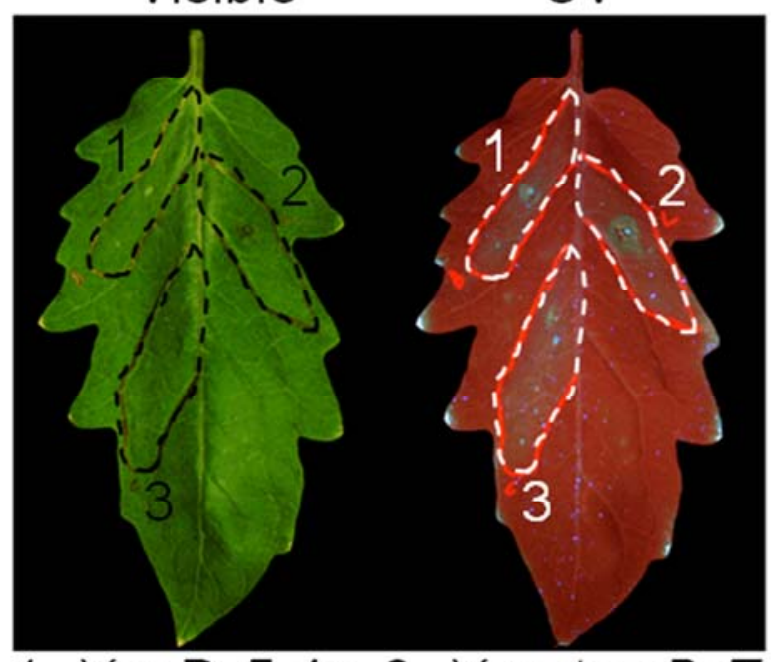

1. Xcv Bv5-4a 2. Xcv $\triangle a v r B s T$

3. Xcv $\triangle a v r B s T$ (avrBsT)

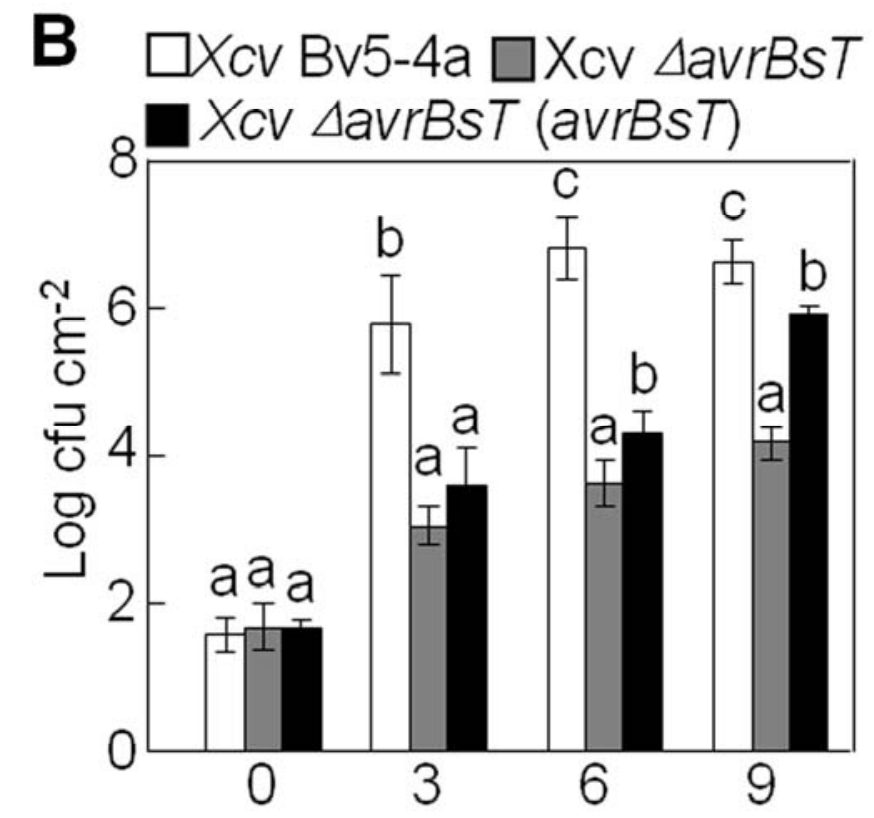

Days after inoculation

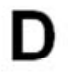

D

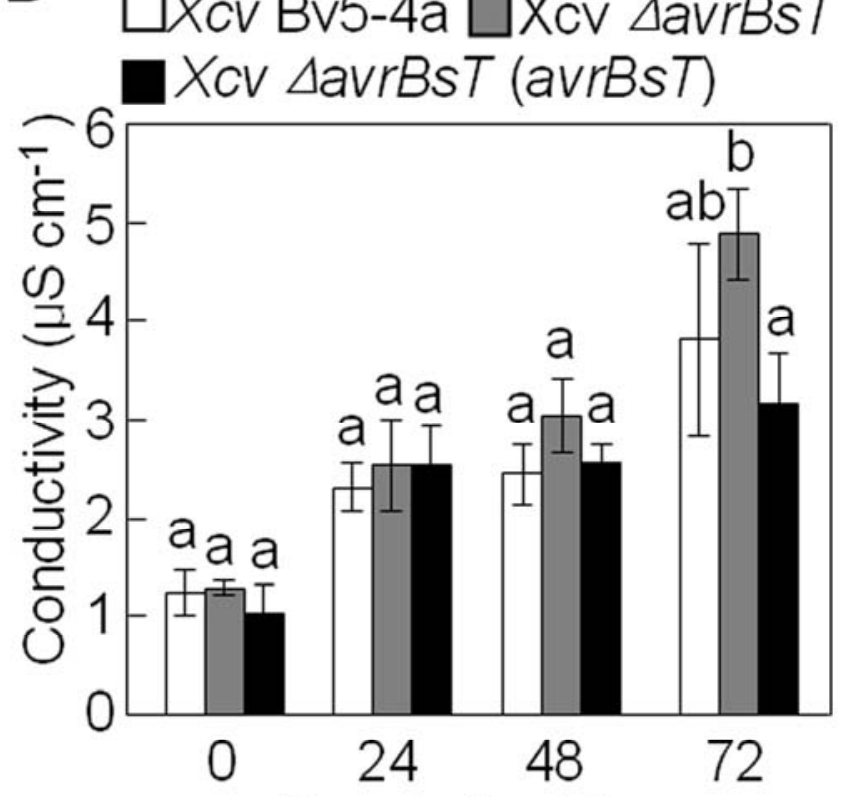

Hours after inoculation

Fig. 5. AvrBsT functions as an important virulence factor of the Xanthomonas campestris pv. vesicatoria Bv5-4a in tomato leaves. A, Disease symptoms of tomato leaves caused by $X$. campestris pv. vesicatoria strains. Tomato leaves were inoculated with the indicated strains $\left(5 \times 10^{4} \mathrm{CFU}\right.$ ml $\left.{ }^{-1}\right)$ and photographed 12 days later. B, Measurement of bacterial growth. Tomato leaves were inoculated with the indicated strains $\left(5 \times 10^{4} \mathrm{CFU} \mathrm{ml}^{-1}\right)$. Bacterial growth in leaves was measured at different time points after inoculation. Different letters indicate statistically significant differences (least significant difference [LSD]; $P<$ 0.05). C, Response of tomato leaves to high bacterial titers. Tomato leaves were inoculated with the indicated strains $\left(5 \times 10^{7} \mathrm{CFU}^{-1}\right)$ and photographed 36 h later. D, Measurement of electrolyte leakage. Tomato leaves were inoculated with indicated strains $\left(5 \times 10^{7} \mathrm{CFU}^{-1}\right)$. Electrolyte leakage caused by cell death was monitored at the indicated time points after inoculation. Different letters indicate statistically significant differences $($ LSD; $P<0.05)$. 


\section{AvrBsT promotes virulence}

of $X$. campestris pv. vesicatoria Ds1 in tomato leaves.

To examine virulence function of AvrBsT in tomato, we inoculated tomato leaves with a low titer $\left(5 \times 10^{4} \mathrm{CFU} \mathrm{ml}^{-1}\right)$ of $X$. campestris pv. vesicatoria strains Ds1, Ds1 (EV), Ds1 (avrBsT), and Bv5-4a. Fourteen days after inoculation, Ds1 (avrBsT) and Bv5-4a produced mild and severe susceptible chloroses, respectively, in tomato leaves whereas tomato leaves infected with Ds1 and Ds1 (EV) did not show any visible symptoms (Fig. 4A). Under UV illumination, a yellowish coloration was visible only in leaves inoculated with Bv5-4a and Ds1 (avrBsT). Bacterial growth in leaf tissues was measured over 9 days after inoculation (Fig. 4B). The growth of Ds1 $(a v r B s T)$ in tomato leaves was significantly promoted compared with that of Ds1 and Ds1 (EV). Ds1 (avrBsT) exhibited 10-fold higher bacterial growth in leaf tissues than did Ds1 and Ds1 (EV) during infection.

Two days after infiltration with a high titer $\left(5 \times 10^{7} \mathrm{CFU}\right.$ $\mathrm{ml}^{-1}$ ) of $X$. campestris pv. vesicatoria strains, no visible symp- toms were produced in tomato leaves (Fig. 4C). However, UV illumination revealed that Ds1 and Ds1 (EV) elicited a stronger accumulation of fluorescent phenolics at leaf inoculation sites than did Ds1 (avrBsT) and Bv5-4a (Fig. 4C). Infection with Ds1 and Ds1 (EV) significantly induced electrolyte leakage from tomato leaf tissues $72 \mathrm{~h}$ after infiltration compared with Bv5-4a- and Ds1 (avrBsT)-infiltrated leaves (Fig. 4D).

To examine the effects of AvrBsT on the early response of plant cells to $X$. campestris pv. vesicatoria infection, histochemical analyses were performed on tomato leaves inoculated with a high titer $\left(5 \times 10^{7} \mathrm{CFU} \mathrm{m}{ }^{-1}\right)($ Fig. 4E). At $12 \mathrm{~h}$ after inoculation, Ds1 and Ds1 (EV) triggered significantly higher callose deposition in leaf tissues than did Ds1 (avrBsT) and Bv5-4a. However, neither distinct DAB nor trypan blue pigmentation was detectable on tomato leaves 24 and $36 \mathrm{~h}$, respectively, after inoculation with any of the $X$. campestris pv. vesicatoria strains tested (Fig. 4E). This supports the notion that strain Ds1 is relatively less virulent than Bv5-4a but not avirulent to tomato plants. Together, these results suggest that

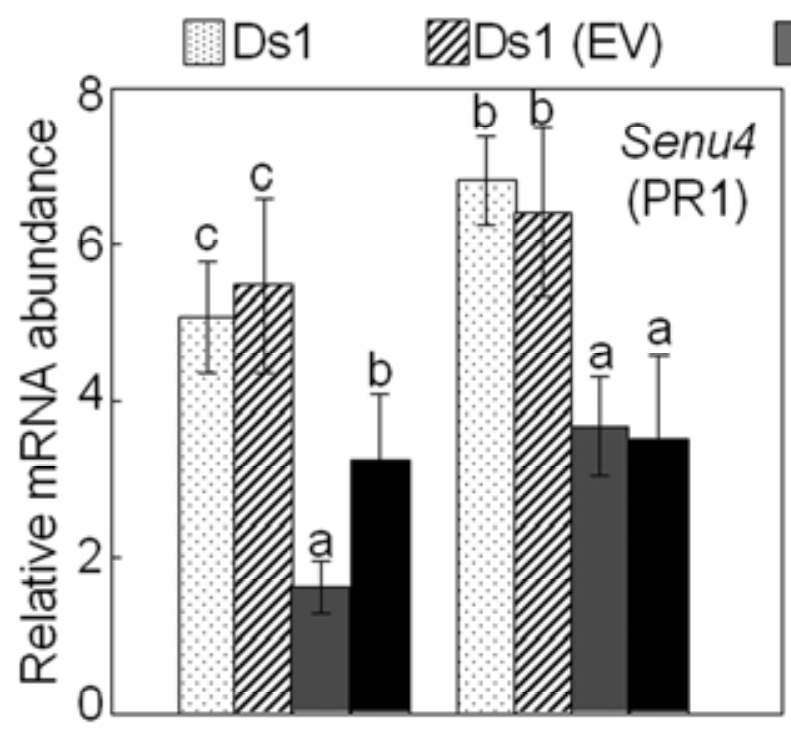

Ds1 (avrBsT) घBv5-4a
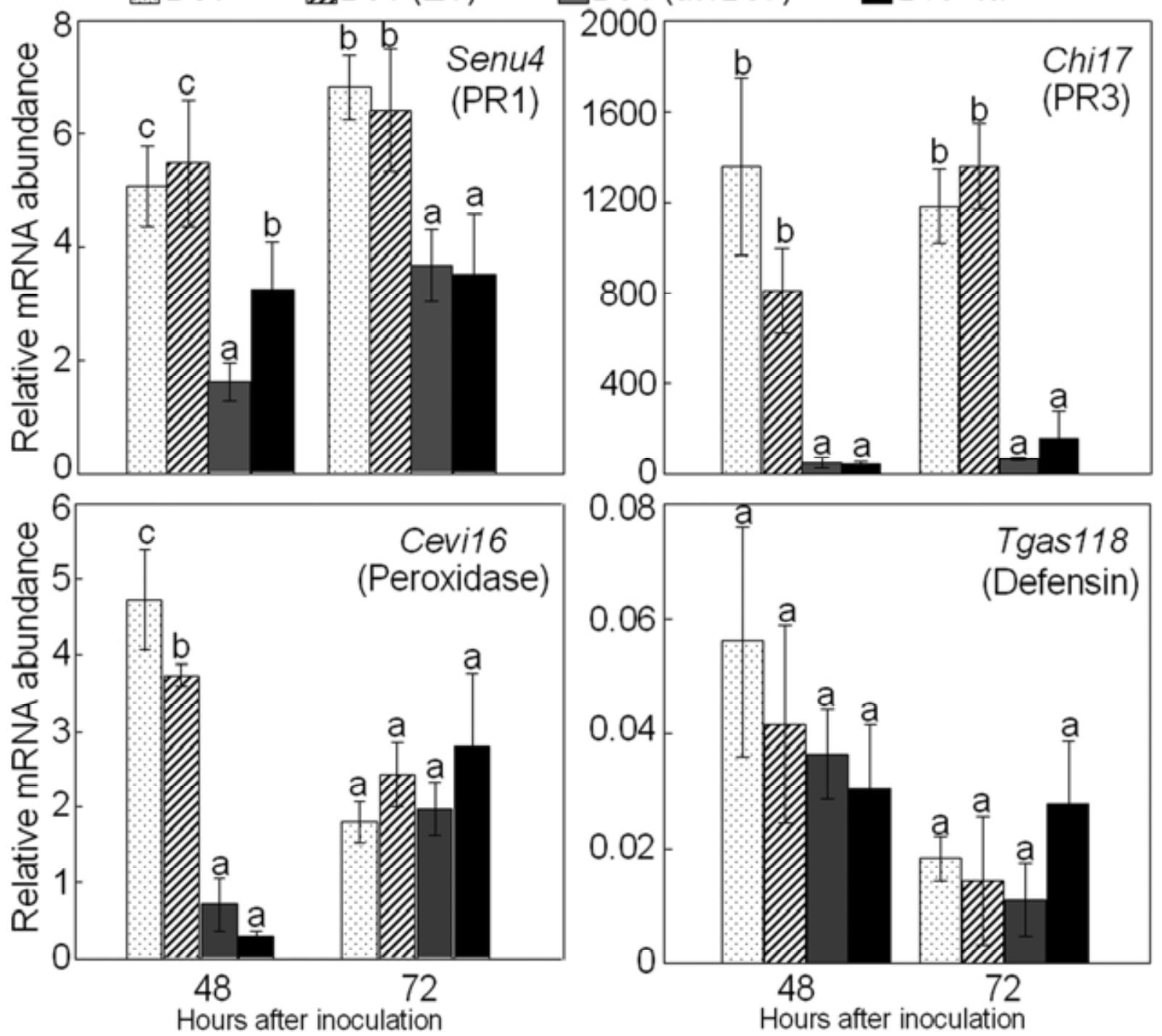

Fig. 6. AvrBsT inhibits induction of defense-related genes in tomato leaves. Total RNA was isolated from tomato leaves inoculated with the Xanthomonas campestris pv. vesicatoria strains Ds1, Ds1 (empty vector [EV]), Ds1 (avrBsT), and Bv5-4a $\left(5 \times 10^{7} \mathrm{CFU}^{-1}\right)$. Quantitative real-time polymerase chain reaction was performed for tomato defense-related genes, including Senu4 (PR1), Chil7 (PR3), Cevil6 (peroxidase), and Tgas118 (defensin). mRNA levels of the tomato actin gene were used for normalization of mRNA abundance of the tested genes. Different letters indicate statistically significant differences (least significant difference; $P<0.05)$. Experiments were repeated three times with similar results. Data are means \pm standard deviations from three independent experiments. 
expression of avrBsT in Ds1 confers enhanced virulence to tomato plants.

\section{AvrBsT is an important virulence factor \\ of $X$. campestris pv. vesicatoria Bv5-4a in tomato leaves.}

To determine the effect of $a v r B s T$ deletion from strain Bv5$4 \mathrm{a}$, tomato leaves were infiltrated with a low titer $\left(5 \times 10^{4}\right.$ $\mathrm{CFU} \mathrm{ml}{ }^{-1}$ ) of the strains Bv5-4a, Bv5-4a $\Delta a v r B s T$, and Bv5-4a $\triangle a v r B s T$ (avrBsT) (Fig. 5A). Twelve days after inoculation, Bv5-4a and Bv5-4a $\triangle a v r B s T$ (avrBsT) induced severe bacterial chlorosis, whereas Bv5-4a $\Delta a v r B s T$ produced mild symptoms on tomato leaves. Bacterial growth also was measured $0,3,6$, and 9 days after inoculation (Fig. 5B). The growth of Bv5-4a $\triangle a v r B s T$ significantly decreased 10 -fold lower than that of Bv5-4a and Bv5-4a $\triangle a v r B s T$ (avrBsT) during infection. This indicates that the deletion of $a v r B s T$ from Bv5-4a significantly reduced its virulence in tomato plants.

Infiltration with a high titer $\left(10^{8} \mathrm{CFU} \mathrm{ml}^{-1}\right)$ of Bv5-4a, Bv54a $\triangle a v r B s T$.and Bv5-4a $\triangle a v r B s T$ (avrBsT) neither exhibited HR nor accumulated fluorescent phenolics at the sites of infiltration in tomato leaves (Fig. 5C). Tomato leaves also were challenged with a high titer $\left(5 \times 10^{7} \mathrm{CFU} \mathrm{ml}{ }^{-1}\right)$ of these $X$. campestris pv. vesicatoria strains (Fig. 5D). Only Bv5-4a $\triangle a v r B s T$ infection significantly induced increased electrolyte leakage from the leaves $72 \mathrm{~h}$ after infiltration. However, tomato leaves infiltrated with Bv5-4a and Bv5-4a $\Delta a v r B s T$ (avrBsT) exhibited gradually increased electrolyte leakage during infection.

\section{AvrBsT inhibits induction \\ of defense-related gene expression in tomato leaves.}

To determine whether the enhanced virulence of strain Ds1 $(a v r B s T)$ is due to the altered defense response of tomato plants, we analyzed the transcript levels of defense-related genes Senu4 (PR1) (Cunnac et al. 2007), Chi17 (PR3) (Cunnac et al. 2007), Cevil6 (peroxidase) (Gadea et al. 1996), and Tgas118 (defensin) (van den Heuvel et al. 2001) in tomato leaves infected with different $X$. campestris pv. vesicatoria strains (Fig. 6). Expression of avrBsT in Ds1 significantly decreased the induction of $P R 1$ and $P R 3$ in tomato leaves during $X$. campestris pv. vesicatoria infection compared with that with Ds1 and Ds1 (EV). In particular, PR3 transcript levels were strikingly low in tomato leaves 48 and $72 \mathrm{~h}$ after inoculation with Ds1 (avrBsT) and Bv5-4a. The tomato peroxidase gene Cevil6 is induced by viroid infection (Gadea et al. 1996). Transcription levels of Cevil6 drastically declined in tomato leaves $48 \mathrm{~h}$ after inoculation with Ds1 (avrBsT) and Bv5-4a. However, AvrBsT did not significantly affect the transcript levels of the tomato defensin gene Tgas118. These data indicate that AvrBsT promotes virulence of the transformed Ds1 strain, leading to the downregulation of defense marker genes in tomato plants.

\section{Transient expression \\ of $a v r B s T$ in pepper and tomato plants.}

The cell-death-inducing activity of AvrBsT was evaluated by the Agrobacterium spp.-mediated transient expression of avrBsT in pepper leaves. As expected, cell death was developed around the sites infiltrated with Agrobacterium spp. carrying the p35S:avrBsT:8Myc (35S:avrBsT) construct but not the p35S:8Myc construct (35S:00) (Fig. 7A). AvrBsT used for transient expression was tagged with the cMyc epitope, and expression of AvrBsT in pepper leaves was confirmed by Western blotting with an anti-cMyc antibody (Fig. 7C). Fluorescent pigments were also strongly induced around the $a v r B s T$ expressing regions (Fig. 7A, UV). Electrolyte leakage measurement and histochemical DAB staining revealed significantly strengthened cell death and $\mathrm{H} 2 \mathrm{O} 2$ burst, respectively, in AvrBsTexpressing pepper leaf tissues (Fig. 7B and D). These results indicate that expression of AvrBsT alone was able to trigger the HR-like cell death response in pepper leaves.

The activity of AvrBsT in tomato leaves was also evaluated. Agrobacterium spp.-mediated transient expression of AvrBsT did not induce cell death and reactive oxygen species (ROS) burst in tomato leaves (Fig. 7E through H). Electrolyte leakage was measured to quantify cell death response. Infiltration with Agrobacterium spp. did not significantly induce electrolyte leakage from tomato leaf tissues (Fig. 7F). Transient expression of AvrBsT in tomato leaves was confirmed by Western blotting with the anti-cMyc antibody (Fig. 7G). In contrast to the response of pepper leaves, tomato leaves did not produce $\mathrm{H}_{2} \mathrm{O}_{2}$, as revealed by DAB staining (Fig. $7 \mathrm{H}$ ). These results indicate that the expression of AvrBsT did not trigger the cell death response in tomato leaves, unlike in pepper leaves.

\section{Full-length AvrBsT is required for plant cell death.}

To characterize the function of AvrBsT during cell death, a series of $\mathrm{N}$-terminal and C-terminal deletion mutants was tested using the Agrobacterium tumefaciens GV3101 (Fig. 8). When transiently expressed, full-length AvrBsT induced cell death in $N$. benthamiana leaves. However, all of the deletion mutants failed to elicit cell death (Fig. 8), indicating that AvrBsT requires the enzymatic domain and the $\mathrm{N}$-terminal and $\mathrm{C}$-terminal regions to trigger cell death.

\section{DISCUSSION}

Pathogenic gram-negative bacteria have various virulence factors, such as effector proteins, toxins, and degradative enzymes, which allow them to invade plants (Barras et al. 1994; Wolpert et al. 2002; Göhre and Robatzek 2008). The TTSS, which delivers effector proteins into host cells, is critical during pathogenesis. Mutant bacteria lacking a TTSS are unable to secrete effector proteins into host cells and, thus, are avirulent. Some effectors trigger the HR in host plants that express cognate $R$ genes; however, hosts lacking $R$ genes fail to recognize the effectors and become diseased (Göhre and Robatzek 2008). AvrBsT, a type III effector of $X$. campestris pv. vesicatoria, is secreted via a TTSS and delivered into plant cells during infection (Escolar et al. 2001). To define the in planta function of AvrBsT, we cloned avrBsT from $X$. campestris pv. vesicatoria Bv5-4a and introduced it into $X$. campestris pv. vesicatoria Ds1, which is highly virulent to pepper plants. This transformant, Ds1 (avrBsT), induced cell death in pepper leaves. The virulence of Ds1 ( $a v r B s T)$ was compromised by AvrBsT expression; however, this strain was more virulent in pepper leaves than was the avirulent strain Bv5-4a. These data suggest that the avirulent strain Bv5-4a may contain other unidentified avirulence factors in addition to AvrBsT. As expected, the decreased virulence of Ds1 (avrBsT) may result from AvrBsTinduced cell death of pepper plants. Ds1 (avrBsT) induced more severe and rapid cell death in pepper leaves than did wild-type Ds1, although not to the level caused by the Bv5-4a, the origin of avrBsT. Early defense indicators, such as callose deposition and generation of ROS, were also induced in pepper leaves during Ds1 ( $a v r B s T)$ infection, which suggests that AvrBsT triggers HR-like cell death responses in pepper leaves. Decreased HR-like cell death induced by Bv5-4a $\Delta a v r B s T$ infection in pepper leaves also supports this notion. Defense responses elicited by AvrBsT seem likely to be closely related to ROS generation and the SA- and jasmonic acid-mediated signaling pathways. Infection with Ds1 (avrBsT) and Bv5-4a led to a strong induction of SA-induced pepper defense marker genes, CaBPRl (PR1) and CaSAR82A (SAR8.2), 12 and $36 \mathrm{~h}$ 

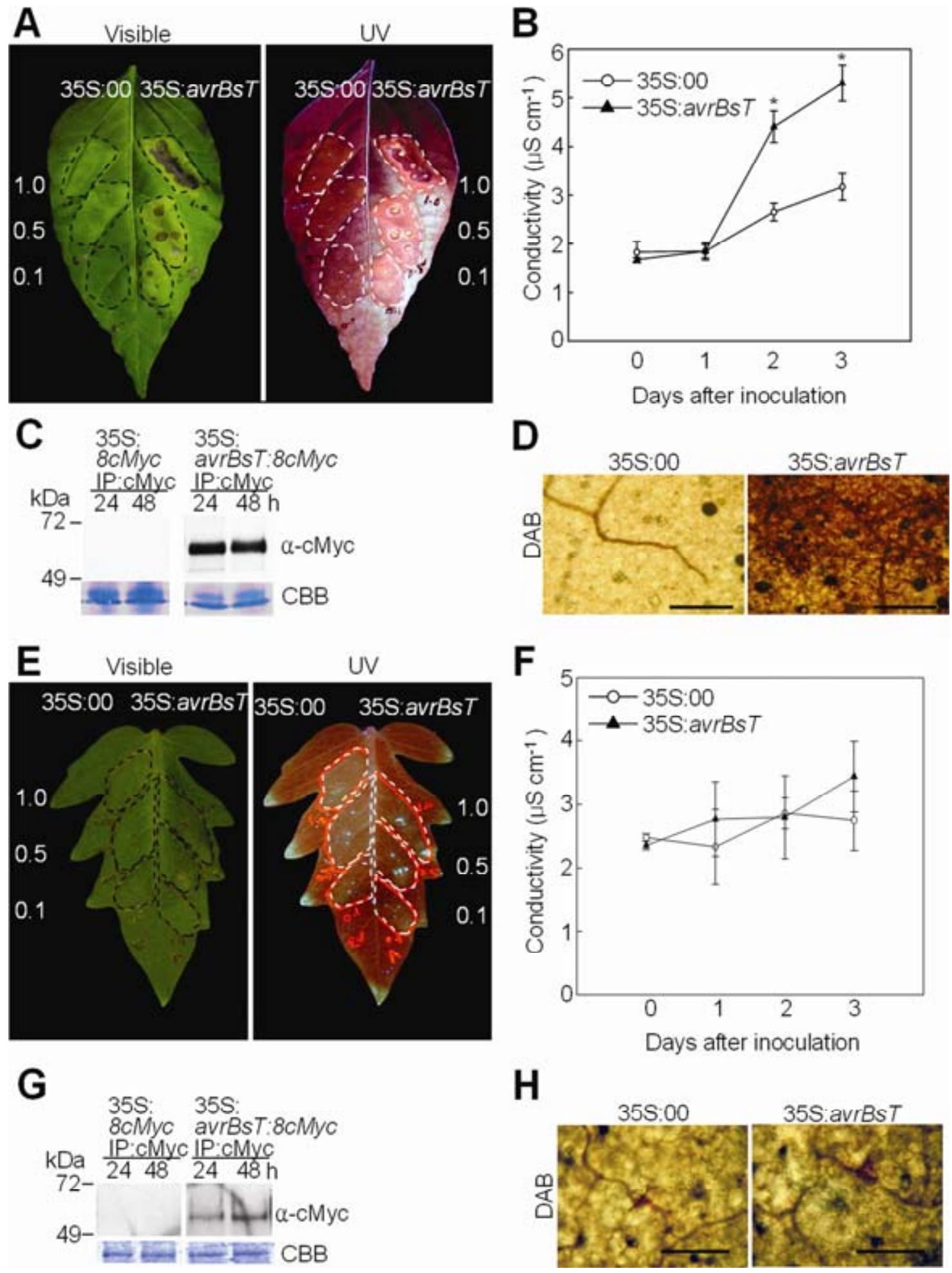

Fig. 7. Transient expression of AvrBsT in pepper leaves. A, Induction of the cell death phenotype by AvrBsT 5 days after infiltration with Agrobacterium spp. carrying the indicated constructs at titers of an optical density at $600 \mathrm{~nm}\left(\mathrm{OD}_{600}\right)=1,0.5$, and 0.1 into pepper leaves. B, Electrolyte leakage measurement. Pepper leaves were infiltrated with Agrobacterium spp. carrying 35S:8Myc (empty vector control) or 35S:avrBsT:8Myc at the titer of $\mathrm{OD}_{600}=1.0$. Electrolyte leakage caused by cell death was monitored at the indicated time points after infiltration. C, Protein was extracted from Agrobacterium spp.-infiltrated pepper leaves and subjected to Western blotting. AvrBsT was detected using an anti-cMyc antibody that binds to the cMyc-epitope tag introduced for vector construction. D, Reactive oxygen species (ROS) formation in pepper leaves. Leaves harvested 3 days after agroinfiltration were stained with 3,3'-diaminobenzidine $(\mathrm{DAB})$. Bars $=250 \mu \mathrm{m}$. E, Expression of AvrBsT in tomato leaves infiltrated with Agrobacterium spp. at the titers of $\mathrm{OD}_{600}=1,0.5$, and 0.1 into tomato leaves. Pictures were taken 5 days after infiltration. F, Electrolyte leakage measurement. Tomato plants were infiltrated with Agrobacterium spp. carrying 35S:8Myc (empty vector control) or 35S:avrBsT:8Myc at the titer of $\mathrm{OD}_{600}=1.0$. Electrolyte leakage was monitored at the indicated time points after infiltration. Asterisks indicate statistically significant differences $(t$ test; $P<0.05)$. G, Protein was extracted from Agrobacterium spp.-infiltrated tomato leaves and subjected to Western blotting. AvrBsT was detected using the anti-cMyc antibody. H, ROS formation in tomato leaves. Leaves harvested 3 days after agroinfiltration were stained with DAB. Bars $=250 \mu \mathrm{m}$. Experiments were repeated three times with similar results. Data in B and F are means \pm standard deviations from three independent experiments. 
after inoculation. Surprisingly, Ds1 (avrBsT) induced higher transcript levels of these defense marker genes than did strain Bv5-4a at early stages of infection. Expression of the peroxidase gene $\mathrm{CaPO} 2$ regulates ROS generation and cell death induction in pepper leaves (Choi et al. 2007). Infection with Ds1 (avrBsT) also induced significantly higher levels of $\mathrm{CaPO} 2 \mathrm{mRNA}$ than did Ds1 and Ds1 (EV), suggesting the involvement of CaPO2dependent ROS generation and cell death regulation upon recognition of AvrBsT by pepper plants. The decrease in mRNA abundance of $\mathrm{CaPO} 2$ from 12 to $36 \mathrm{~h}$ by infection with the virulent strains Ds1 and Ds1 (EV) supports the notion that Ds1 possesses unknown virulent factors responsible for lowering CaPO2 transcript accumulation and the cell death response. Collectively, AvrBsT in pepper plants may function as an avirulent factor that causes HR-like cell death, accompanied by callose deposition, ROS generation, and the induction of defense-related genes.

In contrast to the interactions of $X$. campestris pv. vesicatoria with pepper plants, $X$. campestris pv. vesicatoria strains Ds1, Ds1 (EV), Ds1 (avrBsT), and Bv5-4a were able to colonize tomato plants and cause susceptible symptoms. All four strains inoculated into tomato leaves restricted early ROS generation during the infection process. However, Ds1 (avrBsT) grew well and caused susceptible responses in tomato leaves compared with Ds1 or Ds1 (EV). These results suggest that AvrBsT does not function as an avirulence factor in tomato plants. During infection with different $X$. campestris pv. vesicatoria strains at high titers, AvrBsT seemed to delay the induction of cell death in tomato leaves. Cell death induction was monitored by measuring electrolyte leakage from leaves inoculated with strains Ds1, Ds1 (EV), Ds1 (avrBsT), and Bv54a. At $72 \mathrm{~h}$ after inoculation, $X$. campestris pv. vesicatoria strains lacking avrBsT began to induce cell death in tomato plants. The electrolyte leakage induced by Ds1 (avrBsT) was similar to that of Bv5-4a. The early defense responses to these $X$. campestris pv. vesicatoria strains were evaluated in tomato plants as in pepper plants. Neither ROS nor cell death generation was detectable in tomato leaves inoculated with strains Ds1, Ds1 (EV), Ds1 (avrBsT), and Bv5-4a. However, callose deposition profiles were significantly different for the inoculated strains. Bv5-4a induced the lowest level of callose deposition in tomato leaves. Callose deposition was slightly higher in leaves inoculated with Ds1 (avrBsT) compared with leaves inoculated with Bv5-4a but significantly lower than those inoculated with Ds1 and Ds1 (EV). These results support the notion that AvrBsT suppresses basal defense of tomato plants. The growth of Bv5-4a $\triangle a v r B s T$, in which $a v r B s T$ was deleted, was retarded in tomato plants compared with that of the wildtype strain Bv5-4a, suggesting that AvrBsT functions as an important virulence factor in tomato plants. Notably, abundance of mRNAs of $P R 1$ and $P R 3$ in tomato leaves was greatly reduced by infection with Ds1 (avrBsT) and Bv5-4a. Cevil6 (peroxidase), which is induced in viroid-infected tomato (Gadea et al. 1996), was also drastically downregulated $48 \mathrm{~h}$ after inoculation with Ds1 (avrBsT) and Bv5-4a. Together, these data suggest that AvrBsT functions as a virulence factor in tomato plants to suppress early defense signaling.

AvrBsT cloned from the strain Bv5-4a differed in two amino acid residues compared with the sequence previously reported by Ciesiolka and associates (1999). However, transient expression of AvrBsT in pepper plants induced cell death similar to that observed by Escolar and associates (2001). Cell death induction by AvrBsT has been shown to require a functional catalytic domain (Orth et al. 2000). However, the central domain of AvrBsT, which is collinear with the YopJ serine/ threonine acetyltransferase, may be responsible for enzymatic activity but might not induce cell death in plants. The $\mathrm{N}$ - and C-terminal regions are required to induce cell death in $N$. benthamiana, raising the possibility that these domains may be essential for binding of AvrBsT to host target proteins. Individual domains or regions may not be sufficient to trigger cell death in plants. In contrast, expression of AvrBsT in tomato leaves did not induce hypersensitive cell death, suggesting the absence of the receptor components necessary to bind AvrBsT in tomato cells. Therefore, the cell death response in $N$. benthamiana leaves caused by AvrBsT may result from a hostspecies-dependent recognition process.

Many effector proteins that function as plant immunity and disease susceptibility factors have been identified in the interactions of pathogens with host species (Göhre and Robatzek 2008). In this study, we show that AvrBsT from strain Bv5-4a triggers HR in pepper and $N$. benthamiana plants. This suggests that pepper and $N$. benthamiana plants may contain certain AvrBsT recognition factors which are lacking in tomato plants. Certain host factors, such as a conserved carboxylesterase, a suppressor of AvrBsT-elicited resistance 1 (SOBER1) in Arabidopsis, could be involved in HR triggered by AvrBsT in both pepper and $N$. benthamiana, as observed in Arabidopsis plants (Cunnac et al. 2007). However, in tomato plants, AvrBsT not only suppresses basal defense but also significantly enhances $X$. campestris pv. vesicatoria growth. In further studies, it will be very interesting to identify virulence targets of AvrBsT from tomato plants. Taken together, our findings suggest that AvrBsT is differentially recognized as avirulence and virulence factors by pepper and tomato plants, respectively. Finding and identifying the signaling mechanisms underlying the recognition of AvrBsT will be pivotal for understanding the evolutionary machinery governing the effector-defense complex.
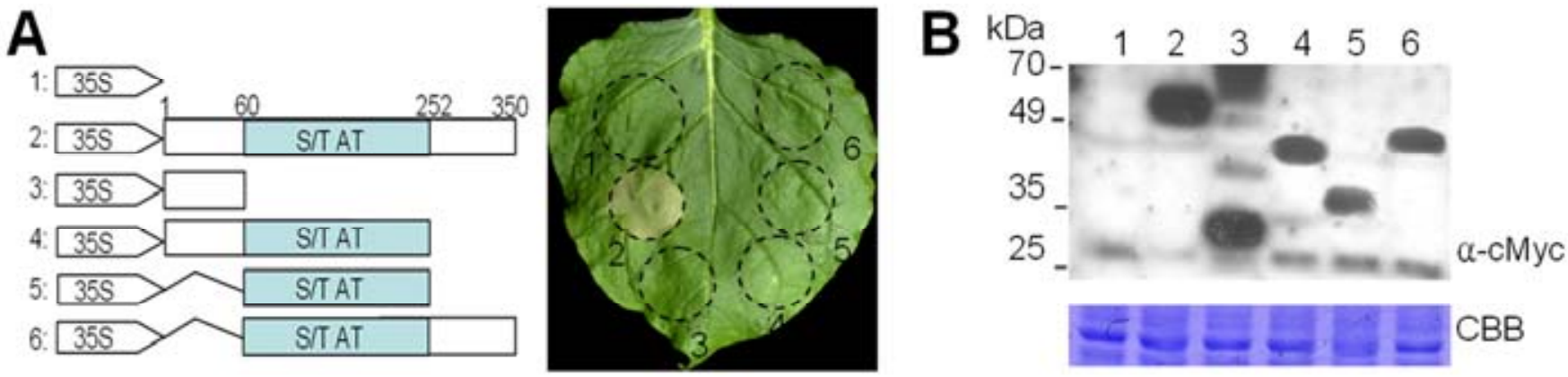

Fig. 8. AvrBsT induces cell death in leaves of Nicotiana benthamiana. A, Transient expression of AvrBsT deletion mutants. An Agrobacterium sp. carrying the indicated constructs at a titer of optical density at $600 \mathrm{~nm}=0.5$ was infiltrated into $N$. benthamiana leaves, which were photographed $48 \mathrm{~h}$ later. B, Immunoblot analyses of AvrBsT deletion mutants. Proteins were extracted from $N$. benthamiana leaves infiltrated with an Agrobacterium sp. carrying the indicated constructs, followed by Western blotting. AvrBsT was detected using the anti-cMyc antibody. Numbers above the Western blot image represent the constructs indicated in A. 


\section{MATERIALS AND METHODS}

\section{Plant materials and growth conditions.}

Pepper (C. аппиит L., cv. Nockwang), tomato (Lycopersicon esculentum, cv. Sunmyung), and $N$. benthamiana were planted in plastic pots ( $8 \mathrm{~cm}$ in diameter) containing a soil mix (loam soil/perlite/vermiculite, 3:1:1, vol/vol/vol). Plants were grown at $28^{\circ} \mathrm{C}$ with a long-day scheme $(16 \mathrm{~h}$ of light and $8 \mathrm{~h}$ of darkness) at a light intensity of $100 \mu \mathrm{mol}$ photons $\mathrm{m}^{-2} \mathrm{~s}^{-1}$.

\section{Pathogenic bacterial strains.}

Strains Ds1 and Bv5-4a of X. campestris pv. vesicatoria were used. Strain Ds1 was isolated in 1991 from pepper plants in Korea (Hwang et al. 1995). Strain Bv5-4a was generously provided by R. E. Stall, Department of Plant Pathology, University of Florida, Gainesville.

\section{Plasmid construction.}

To clone avrBsT into the TOPcloner Blunt V2 vector (Enzynomics, Daejeon, Korea) for use as a template, the avrBsT ORF was amplified from $X$. campestris pv. vesicatoria Bv5-4a using Pyrococcus furiosus DNA polymerase (Enzynomics) and the primers ATGAAGAATTTTATGCGTTCACTTG (F, forward) and TTATGATTCAATAGTTTTCCTAATTTT (R, reverse). The amplicon generated with primers F, GAGACT CGAGATGAAGAATTTTATGCGTTCACTT and R, GAGA GGATCCTTATGATTCAATAGTTTTCCTAATTTT, which contains $X h o \mathrm{I} /$ Bam HI sites flanking the avrBsT ORF, was digested with $\mathrm{XhoI} /$ BamHI and ligated into the vector pBBR1MCS-2 (Kovach et al. 1995). A new vector, p35S8 myc, was constructed to generate myc-tagged avrBsT. The DNAs coding for $4 \times m y c$ with $K p n \mathrm{I} / N d e \mathrm{I}$ sites (F primer, GCGGTACCAAAGCTATGGAGCAAAAGC and R primer, GCCATATGGCCCAAGCTCTCCATTTC) or NdeI/SacI (F primer, GCCATATGAAAGCTATGGAGCAAAAGC and R primer, GCGAGCTCCTAGCCCAAGCTCTCCATTT) were amplified from the vector myc-pBA and ligated at the NdeI site with the other myc DNA to generate an $8 \times m y c$ fragment. pSPYNE-35S (Walter et al. 2004) was digested with $\mathrm{KpnI} / \mathrm{SacI}$ to remove a yellow fluorescent protein fragment and ligated to the $8 \times$ myc fragment to produce p35S-8myc. AvrBsT with a deletion of the termination codon and incorporation of SpeI/XhoI sites (F primer, GAGAACTAGTATGA AGAATTTTATGCGTTCACTTG and R primer, GAGACTC GAGTGATTCAATAGTTTTCCTAATTTTCC) was amplified and ligated to p35S-8myc. Primers F, GAGACTCGAG ATGAAGAATTTTATGCGTTCACTT and R, GAGAGGAT CCCTAGCCCAAGCTCTCCATTT, encompassing avrBsT and $8 \times m y c$, were used to amplify an $a v r B s T: 8 \times$ myc fusion construct $(\mathrm{Xhol} /$ BamHI), which was ligated to pBBR1MCS-2. Various deletion mutants of avrBsT (SpeI/XhoI) were generated by polymerase chain reaction (PCR) and subcloned into p35S-8myc using the primers GAGAACTAGTATGA AGAATTTTATGCGTTCACTTG (F1), GAGAACTAGTAT GGCTATTGCGCTGGAAGAATCGCT (F2), GAGACTCG AGATTTGAACTATTCAGCGATTCTTCC (R1), GAGACT CGAGTCGAACGTTTCTTCTTAAACAATC (R2), and GA GACTCGAGTGATTCAATAGTTTTCCTAATTTTCC (R3). Amplified DNA fragments were confirmed by sequencing. For generation of the $X$. campestris $\mathrm{pv}$. vesicatoria Bv5-4a $\triangle a v r B s T$ mutant, the 475-bp fragment of avrBsT was amplified by PCR using P. furiosus DNA polymerase and the following primer pairs: knock-out forward (5'-GAATTCGAAAT GCGGATGTATGCGGA-3') and knock-out reverse (5'-GAA TTCTAAGCGCACAGAGCCATATT-3'). The amplified fragment of avrBsT was digested with EcoRI and cloned into the pVIT321 suicide vector. The resulting construct was used for biparental mating to generate Bv5-4a $\triangle a v r B s T$ (Lee et al. 2009). For generation of the Ds1 $\Delta h r c V$ mutant, the 617-bp fragment of $h r c V$ was amplified by PCR using P. furiosus DNA polymerase and the following primer pairs: knock-out forward (5'-GAATTCGCCGGCGTCATGATCACC-3') and knock-out reverse (5'-GAATTCTCCTGGATGCCGACGAAC A-3'). The amplified fragment of $h r c V$ was digested with EcoRI and cloned into the pVIT321 vector. The resulting construct was used for biparental mating to generate Ds1 $\Delta h r c V$.

\section{Bacterial transformation.}

$X$. campestris pv. vesicatoria strains Ds1 and Bv5-4a were grown overnight in yeast nutrient (YN) media $(5 \mathrm{~g}$ of yeast extract and nutrient broth at $8 \mathrm{~g} \mathrm{liter}^{-1}$ ) at $28^{\circ} \mathrm{C}$. Ds1 and Bv54a cultures were centrifuged and washed twice with sterile water. Plasmids pBBR1MCS-2, pBBR1MCS-2:avrBsT or pBBR1MCS-2:avrBsT:8x myc were introduced into competent $X$. campestris pv. vesicatoria cells using a MicroPulser (BioRad, Hercules, CA, U.S.A.), which were then grown at $28^{\circ} \mathrm{C}$ on $\mathrm{YN}$ agar containing kanamycin (Kan) at $50 \mathrm{mg} \mathrm{liter}^{-1}$. Various avrBsT constructs were also transformed into competent A. tumefaciens GV3101 and grown at $28^{\circ} \mathrm{C}$ on Luria-Bertani agar containing rifampicin (Rif) at $50 \mathrm{mg} \mathrm{liter}^{-1}$ rifampicin (Rif) and Kan at $50 \mathrm{mg} \mathrm{liter}^{-1}$.

Biparental mating was used to generate $X$. campestris pv. vesicatoria Bv5-4a $\Delta a v r B s T$ and Ds1 $\Delta h r c V$ (Lee et al. 2009). The donor Escherichia coli 17-1 $\lambda$-pir harboring pVIT321: avrBsT or pVIT321:hrcV was mixed with Bv5-4a or Ds1, respectively, and then spread onto $\mathrm{YN}$-agar media without antibiotics. Overnight culture was collected and transformants were selected by spreading on YN agar containing tetracycline (Tc) at $5 \mathrm{mg} \mathrm{liter}^{-1}$ and Rif at $50 \mathrm{mg} \mathrm{liter}^{-1}$. To express avrBsT in $X$. campestris pv. vesicatoria strains, the plasmid pBBR1MCS-2:avrBsT was introduced into Bv5-4a $\Delta a v r B s T$ or Ds1 $\Delta h r c V$ by electroporation. Transformants were then selected on the YN agar supplemented with Tc at $5 \mathrm{mg} \mathrm{liter}^{-1}$, Rif at $50 \mathrm{mg} \mathrm{liter}^{-1}$, and Kan at $50 \mathrm{mg} \mathrm{liter}{ }^{-1}$.

\section{Bacterial inoculation.}

$X$. campestris pv. vesicatoria strains Ds1, Ds1 (EV), Ds1 (avrBsT), and Bv5-4a were cultured overnight. The bacteria were harvested and resuspended in $10 \mathrm{mM} \mathrm{MgCl}$ solution, which was infiltrated into pepper and tomato leaves using a needleless syringe (Kim et al. 2007). Bacterial growth in leaves was monitored 0 and 3 days after inoculation with $X$. campestris pv. vesicatoria $\left(5 \times 10^{4} \mathrm{CFU} \mathrm{ml}^{-1}\right)$. Three leaf discs $(1.0 \mathrm{~cm}$ in diameter) were ground in $1 \mathrm{ml}$ of $10 \mathrm{mM}$ $\mathrm{MgCl}_{2}$ sterile solution. The suspension was serial diluted and spread on $\mathrm{YN}$ agar. For transient expression of various avrBsT constructs, Agrobacterium cultures were grown overnight and resuspended in medium $(10 \mathrm{mM}$ morpholineethanesulfonic acid [pH 5.7], $10 \mathrm{mM} \mathrm{MgCl}$, and $0.2 \mathrm{mM}$ acetosyringone) to infiltrate into $N$. benthamiana, pepper, and tomato leaves.

\section{Ion leakage assay.}

Leaves of pepper and tomato plants were harvested at various time points after inoculation with strains Ds1, Ds1 (EV), Ds1 (avrBsT), and Bv5-4a. Leaf discs (0.5 $\mathrm{cm}$ in diameter) were removed with a cork borer and washed in $10 \mathrm{ml}$ of sterile double-distilled water for $30 \mathrm{~min}$ with gentle agitation. Washed leaf discs were transferred to $15 \mathrm{ml}$ of sterile doubledistilled water and incubated for $3 \mathrm{~h}$ at room temperature with gentle agitation. The conductivity of the leaf samples was measured using a Sension 7 conductivity meter (Hach Co., Loveland, CO, U.S.A.). Experiments were carried out three times with similar results. 


\section{Histochemistry}

Callose deposition was visualized by depigmenting the inoculated leaves in $95 \%$ ethanol and staining with $150 \mathrm{mM}$ $\mathrm{K}_{2} \mathrm{HPO}_{4}$ solution ( $\mathrm{pH} 9.5$ ) containing $0.01 \%$ aniline blue for 30 min. $\mathrm{H}_{2} \mathrm{O}_{2}$ production was visualized by placing the inoculated leaves in DAB solution at $1 \mathrm{mg} \mathrm{ml}^{-1}$ (Sigma-Aldrich, St. Louis) for $15 \mathrm{~h}$ (Thordal-Christensen et al. 1997). Chlorophyll was cleared from the stained leaves by boiling in $95 \%$ ethanol. Cell death was monitored by trypan blue staining of healthy or inoculated leaves (Koch and Slusarenko 1990). Leaves were stained with lactophenol-trypan blue solution $(10 \mathrm{ml}$ of lactic acid, $10 \mathrm{ml}$ of glycerol, $10 \mathrm{~g}$ of phenol, and $10 \mathrm{mg}$ of trypan blue, dissolved in $10 \mathrm{ml}$ of distilled water) and destained in chloral hydrate solution (chloral hydrate at $2.5 \mathrm{~g} \mathrm{ml}^{-1}$ ). The samples were photographed using a light microscope mounted with a digital camera (Olympus, Tokyo). Chlorosis, cell death, or phenolic compound accumulation (Park 2005) in leaves was visualized using a hand-held UV lamp (UVP, Upland, CA, U.S.A.).

\section{Quantitative reverse-transcription PCR.}

Total RNA was isolated from leaves inoculated with $X$. campestris pv. vesicatoria strains using Trizol reagent (Invitrogen, Carlsbad, CA, U.S.A.). RNA ( $2 \mu \mathrm{g})$ was used in a reversetranscription reaction with MMLV reverse transcriptase (Enzynomics, Seoul, Korea). Pepper gene-specific primers for CaBPRl (F, CAGGATGCAACACTCTGGTGG; R, ATCAA AGGCCGGTTGGTC), $\mathrm{CaPO2}$ (F, ATGAGTATTTCAAAC AACTCTTTT; R, TTAATTTATAGCTCCACACACAGT), CaSAR82A (F, CAGGGAGATGAATTCTGAGGC; R, CATAT GAACCTCTATGGATTTCTG), CaDEF1 (F, CAAGGGAGTA TGTGCTAGTGAGAC; R, TGCACAGCACTATCATTGCAT AC), and 18S rRNA (F, CCGGTCCGCCTATGGTGTGCACC GGTCGTC; R, GCAGTTGTTCGTCTTTCATAAATCCAAG AA) were used. Tomato gene-specific primers for Actin (F, GAGCGTGGTTACTCGTTCA; R, CTAATATCCACGTCAC ATTTCAT), Senu4 (F, CTGGTGCTGGGGAGAATC; R, GT CCGATCCAGTTGCCTACA), Chil7 (F, AGGCAATCAAAT GGGAAGTG; R, CAATCCGATCCTCCACTTGT) (Cunnac et al. 2007), Cevil6 (F, GTTTTACTGAATCTGTTGCTGC TC; R, TCAGTTGAATGCAGAGCAAACTTT), and Tgas 118 (F, ATGGCAAACTCCATGCGTTTA; R, TTATTCATTCATG AGTATTTCCGAT) were used. Real-time PCR was performed using iQ SYBR Green Supermix and iCycler iQ (Bio-Rad). The 18S rRNA transcript level was used to normalize the transcript level of each gene. Relative expression levels were determined by comparing the values with that of the uninoculated control.

\section{Protein extraction and Western blots.}

Leaves infiltrated with Agrobacterium spp. were harvested and homogenized in liquid nitrogen. Protein extraction buffer (2 ml) containing $50 \mathrm{mM}$ Tris- $\mathrm{Cl}(\mathrm{pH} 8.8), 50 \mathrm{mM} \mathrm{NaCl}, 10$ mM EDTA, $0.2 \%$ Triton $\mathrm{X}-100$, and $1 \times$ protease inhibitor cocktail (Roche, Indianapolis, IN, U.S.A.) was added to $1 \mathrm{~g}$ of each homogenized sample. The samples were centrifuged at $13,000 \times g$ at $4^{\circ} \mathrm{C}$ for $30 \mathrm{~min}$. Supernatants were resolved on a $10 \%$ sodium dodecyl sulfate polyacrylamide gel electrophoresis (SDS-PAGE) gel and transferred to a polyvinylidene difluoride (PVDF) membrane. Western blot analysis was performed using an anti-cMyc-peroxidase conjugate (Sigma-Aldrich).

\section{Type III secretion assay.}

Type III secretion experiments were carried out in M9 minimal medium (Rossier et al.1999). After incubation for $4 \mathrm{~h}$ at $28^{\circ} \mathrm{C}$, cells were pelleted by centrifugation and the supernatant was filtered through a $0.2-\mu \mathrm{m}$ syringe filter. Cellular and super- natant proteins were precipitated according to Rossier and associates (1999), resolved in 12\% SDS-PAGE gels, and transferred to PVDF membranes for Western blot analysis using anti-cMyc (Sigma-Aldrich) and anti-NptII (Abcam, Tokyo) antibodies.

\section{ACKNOWLEDGMENTS}

This research was supported by a grant (CG1133) from the Crop Functional Genomics Center of the 21st Century; the Frontier Research Program funded by the Ministry of Education, Science and Technology of the Republic of Korea; and a grant (20070401034028) from the BioGreen21 Program, Rural Development Administration, Korea. We thank U. Bonas (Martin-Luther-Universität) for Agrobacterium tumefaciens GV3101.

\section{LITERATURE CITED}

An, S. H., Choi, H. W., Hwang, I. S., Hong, J. K., and Hwang, B. K. 2008a. A novel pepper membrane-located receptor-like protein gene CaMRP1 is required for disease susceptibility, methyl jasmonate insensitivity and salt tolerance. Plant Mol. Biol. 67:519-533.

An, S. H., Sohn, K. H., Choi, H. W., Hwang, I. S., Lee, S. C., and Hwang, B. K. 2008b. Pepper pectin methylesterase inhibitor protein CaPMEI1 is required for antifungal activity, basal disease resistance and abiotic stress tolerance. Planta 228:61-78.

Asai, T., Tena, G., Plotnikova, J., Willmann, M. R., Chiu, W. L., GomezGomez, L., Boller, T., Ausubel, F. M., and Sheen, J. 2002. Map kinase signalling cascade in Arabidopsis innate immunity. Nature 415:977-983.

Baker, C. J., O’Neill, N. R., Keppler, L. D., and Orlandi, E. W. 1991. Early responses during plant-bacteria interactions in tobacco cell suspensions. Phytopathology 81:1504-1507

Barras, F., van Gijsegem, F., and Chatterjee, A. K. 1994. Extracellular enzymes and pathogenesis of soft-rot Erwinia. Annu. Rev. Phytopathol. 32:201-234.

Boller, T., and He, S. Y. 2009. Innate immunity in plants: an arms race between pattern recognition receptors in plants and effectors in microbial pathogens. Science 324:742-744.

Choi, H. W., Kim, Y. J., Lee, S. C., Hong, J. K., and Hwang B. K. 2007. Hydrogen peroxide generation by the pepper extracellular peroxidase CaPO2 activates local and systemic cell death and defense response to bacterial pathogens. Plant Physiol. 145:890-904.

Choi, H. W., Lee, B. G., Kim, N. H., Park, Y., Lim, C. W., Song, H. K., and Hwang, B. K. 2008. A role for a menthone reductase in resistance against microbial pathogens in plants. Plant Physiol. 148:383-401.

Choi, H. W., Lee, D. H., and Hwang, B. K. 2009. The pepper calmodulin gene $C a C a M 1$ is involved in reactive oxygen species and nitric oxide generation required for cell death and the defense response. Mol. PlantMicrobe Interact. 22:1389-1400.

Ciesiolka, L. D., Hwin, T., Gearlds, J. D., Minsavage, G. V., Saenz, R., Bravo, M., Handley, V., Conover, S. M., Zhang, H., Caporgno, J., Phengrasamy, N. B., Toms, A. O., Stall, R. E., and Whalen, M. C. 1999. Regulation of expression of avirulence gene $a v r R x v$ and identification of a family of host interaction factors by sequence analysis of avrBsT. Mol. Plant-Microbe Interact. 12:35-44.

Cunnac, S., Wilson, A., Nuwer, J., Kirik, A., Baranage, G., and Mudgett, M. B. 2007. A conserved carboxylesterase is a SUPPRESSOR OF AVRBST-ELICITED RESISTANCE in Arabidopsis. Plant Cell 19:688-705.

DebRoy, S., Thilmony, R., Kwack, Y. B., Nomura, K., and He, S. Y. 2004. A family of conserved bacterial effectors inhibits salicylic acidmediated basal immunity and promotes disease necrosis in plants. Proc. Natl. Acad. Sci. U.S.A. 101:9927-9932.

Desveaux, D., Singer, A. U., Wu, A. J., McNulty, B. C., Musselwhite, L. Nimchuk, Z., Sondek, J., and Dangl, J. L. 2007. Type III effector activation via nucleotide binding, phosphorylation, and host target interaction. PLoS Pathog. 3:456-469.

Do, H. M., Hong, J. K., Jung, H. W., Kim, S. H., Ham, J. H., and Hwang, B. K. 2003. Expression of peroxidase-like genes, $\mathrm{H}_{2} \mathrm{O}_{2}$ production, and peroxidase activity during the hypersensitive response to Xanthomonas campestris pv. vesicatoria in Capsicum annиum. Mol. Plant-Microbe Interact. 16:196-205.

Escolar, L., Ackerveken, G. V. D., Pieplow, S., Rossier, O., and Bonas, U. 2001. Type III secretion and in planta recognition of the Xanthomonas avirulence proteins AvrBs1 and AvrBsT. Mol. Plant Pathol. 2:287-296.

Gadea, J., Mayda, M. E., Conejero, V., and Vera, P. 1996. Characterization of defense-related genes ectopically expressed in viroid-infected tomato plants. Mol. Plant-Microbe Interact. 9:409-15. 
Gimenez-Ibanez, S., Hann, D. R., Ntoukakis, V., Petutschnig, E., Lipka, V., and Rathjen, J. P. 2009. AvrPtoB targets the LysM receptor kinase CERK1 to promote bacterial virulence on plants. Curr. Biol. 19:423429 .

Greenberg, J. T., and Yao, N. 2004. The role and regulation of programmed cell death in plant-pathogen interactions. Cell. Microbiol. 6:201-211.

Göhre, V., and Robatzek, S. 2008. Breaking the barriers: microbial effector molecules subvert plant immunity. Annu. Rev. Phytopathol. 46:180215.

Hwang, B. K., Lee, J. T., Hwang, B. G., and Koh, Y. J. 1995. Restriction fragment length polymorphism analyses of the plasmid DNAs in strains of Xanthomonas campestris pv. vesicatoria from different geographic areas. J. Phytopathol. 143:185-191.

Jamir, Y., Guo, M., Oh, H. S., Petnicki-Ocwieja, T., Chen, S., Tang, X., Dickman, M. B., Collmer, A., and Alfano, J. R. 2004. Identification of Pseudomonas syringae type III effectors that can suppress programmed cell death in plants and yeast. Plant J. 37:554-565.

Jones, J. D. G., and Dangl, J. L. 2006. The plant immune system. Nature 444:323-329.

Jones, J. D. G., and Stall, R. E. 1998. Diversity among Xanthomonads pathogenic on pepper and tomato. Annu. Rev. Phytopathol. 36:41-58.

Jung, H. W., and Hwang, B. K. 2000. Isolation, partial sequencing, and expression of pathogenesis-related cDNA genes from pepper leaves infected by Xanthomonas campestris pv. vesicatoria. Mol. Plant-Microbe Interact. 13:136-142.

Kim, B. S., Kim, Y. C., Shin, K. S., and Kim, J. H. 2007 Near-isogenic lines for genes conferring hypersensitive resistance to bacterial spot in chili pepper. Plant Pathol. J. 23:155-160.

Koch, E., and Slusarenko, A. 1990. Arabidopsis is susceptible to infection by a downy mildew fungus. Plant Cell 2:437-445.

Kovach, M. E., Elzer, P. H., Hill, D. S., Robertson, G. T., Farris, M. A., Martin Roop, R., II, and Peterson, K. M. 1995. Four new derivatives of the broad-host-range cloning vector pBBR1MCS, carrying different antibiotic-resistance cassettes. Gene 166:175-176.

Lee, S. C., and Hwang, B. K. 2003. Identification of the pepper SAR8.2 gene as a molecular marker for pathogen infection, abiotic elicitors and environmental stresses in Capsicum annuum. Planta 216:387-396.

Lee, S. C., and Hwang, B. K. 2005. Induction of some defense-related genes and oxidative burst is required for the establishment of systemic acquired resistance in Capsicum annuum. Planta 221:790-800.

Lee, S. C., Hwang, I. S., Choi, H. W., and Hwang, B. K. 2008. Involvement of the pepper antimicrobial protein $C a A M P 1$ gene in broad spectrum disease resistance. Plant Physiol. 148:1004-1020.

Lee, Y. H., Oh, S. J., and Park, W. J. 2009. Inactivation of the Pseudomonas putida $\mathrm{KT} 2440 d s b A$ gene promotes extracellular matrix production and biofilm formation. FEMS (Fed. Eur. Microbiol. Soc.) Microbiol. Lett. 297:38-48.

Lee, Y. K., Kim Y. J., and Hwang B. K. 1994. Bacterial multiplications and electrophoretic patterns of soluble proteins in compatible and incompatible interactions of pepper leaves with Xanthomonas campestris pv. vesicatoria. Korean J. Plant Pathol. 10:305-313.

Minsavage, G. V., Dahlbeck, D., Whalen, M. C., Kearney, B., Bonas, U., Staskawicz, B. J., and Stall R. E. 1990. Gene-for-gene relationships specifying disease resistance in Xanthomonas campestris pv. vesicatoria-pepper interactions. Mol. Plant-Microbe Interact. 3:41-47.

Mukherjee, S. M., Keitany, G., Li, Y., Wang, Y., Ball, H. L., Goldsmith, E. J., and Orth, K. 2006. Yersinia YopJ acetylates and inhibits kinase activation by blocking phosphorylation. Science 312:1211-1214.

Orth, K., Xu, Z., Mudgett, M. B., Bao, Z. Q., Palmer, L. E., Bliska, J. B., Mangel, W. F., Staskawicz, B., and Dixon, J. E. 2000. Disruption of sig naling by Yersinia effector YopJ, a ubiquitin-like protein protease. Science 290:1594-1597.

Park, J. M. 2005. The hypersensitive response. A cell death during disease resistance. Plant Pathol. J. 21:99-101.

Roden, J., Eardley, L., Hotson, A., Cao, Y., and Mudgett, M. B. 2004 Characterization of the Xanthomonas AvrXv4 effector, a SUMO protease translocated into plant cells. Mol. Plant-Microbe Interact. 17:633643.

Rossier O., Wengelnik, K., Hahn, K., and Bonas, U. 1999. The Xanthomonas Hrp type III system secretes proteins from plant and mammalian bacterial pathogens. Proc. Natl. Acad. Sci. U.S.A. 96:9368-9373.

Thordal-Christensen, H., Zhang, Z., Wei, Y., and Collinge, D. B. 1997 Subcellular localization of $\mathrm{H}_{2} \mathrm{O}_{2}$ in plants: $\mathrm{H}_{2} \mathrm{O}_{2}$ accumulation in papillae and hypersensitive response during the barley-powdery mildew interaction. Plant J. 11:1187-1194.

Van den Heuvel, K. J. P. T., Hulzink, J. M. R., Barendse, G. W. M., and Wullems, G. J. 2001. The expression of tgas118, encoding a defensin in Lycopersicon esculentum, is regulated by gibberellin. J. Exp. Bot. 52:1427-1436.

Walter, M., Chaban, C., Schütze, K., Batistic, O., Weckermann, K., Näke, C., Blazevic, D., Grefen, C., Schumacher, K., Oecking, C., Harter K., and Kudla, J. 2004. Visualization of protein interactions in living plant cells using biomolecular fluorescence complementation. Plant J. 40:428-438.

Wolpert, T. J., Dunkle, L. D., and Ciuffetti, L. M. 2002. Host-selective toxins and avirulence determinants: what's in a name? Annu. Rev. Phytopathol. 40:251-285.

Zhang, J., Shao, F., Li, Y., Cui, H., Chen, L., Li, H., Zou, Y., Long, C. Lan, L., Chai, J., Chen, S., Tang, X., and Zhou, J.-M. 2007. A Pseudomonas syringae effector inactivates MAPKs to suppress PAMP-induced immunity in plants. Cell Host Microbe 1:175-185 